\title{
The Divalent Metal Transporter 1 (DMT1) Is Required for Iron Uptake and Normal Development of Oligodendrocyte Progenitor Cells
}

\author{
Veronica T. Cheli, ${ }^{1 \star} \oplus$ Diara A. Santiago González, ${ }^{1 *}$ Leandro N. Marziali, ${ }^{1 \star}$ Norma N. Zamora, ${ }^{1}{ }^{\oplus}$ María E. Guitart, ${ }^{2}$ \\ Vilma Spreuer, ${ }^{1}$ Juana M. Pasquini, ${ }^{2}$ and $₫$ Pablo M. Paez ${ }^{1}$ \\ ${ }^{1}$ Hunter James Kelly Research Institute, Department of Pharmacology and Toxicology, Jacobs School of Medicine and Biomedical Sciences, The State \\ University of New York, University at Buffalo, Buffalo, New York 14203, and ${ }^{2}$ Department of Biological Chemistry, Biological and Physical Chemistry \\ Institute (IQUIFIB-CONICET). School of Pharmacy and Biochemistry, University of Buenos Aires, Buenos Aires, Argentina 1113
}

The divalent metal transporter 1 (DMT1) is a multimetal transporter with a primary role in iron transport. Although DMT1 has been described previously in the CNS, nothing was known about the role of this metal transporter in oligodendrocyte maturation and myelination. To determine whether DMT1 is required for oligodendrocyte progenitor cell (OPC) maturation, we used siRNAs and the Cre-lox system to knock down/knock out DMT1 expression in vitro as well as in vivo. Blocking DMT1 synthesis in primary cultures of OPCs reduced oligodendrocyte iron uptake and significantly delayed OPC development. In vivo, a significant hypomyelination was found in DMT1 conditional knock-out mice in which DMT1 was postnatally deleted in NG2- or Sox10-positive OPCs. The brain of DMT1 knock-out animals presented a decrease in the expression levels of myelin proteins and a substantial reduction in the percentage of myelinated axons. This reduced postnatal myelination was accompanied by a decrease in the number of myelinating oligodendrocytes and a rise in proliferating OPCs. Furthermore, using the cuprizone model of demyelination, we established that DMT1 deletion in NG2-positive OPCs lead to less efficient remyelination of the adult brain. These results indicate that DMT1 is vital for OPC maturation and for the normal myelination of the mouse brain.

Key words: DMT1; iron uptake; myelination; oligodendrocyte; remyelination

Significance Statement

To determine whether divalent metal transporter 1 (DMT1), a multimetal transporter with a primary role in iron transport, is essential for oligodendrocyte development, we created two conditional knock-out mice in which DMT1 was postnatally deleted in NG2- or Sox10-positive oligodendrocyte progenitor cells (OPCs). We have established that DMT1 is necessary for normal OPC maturation and is required for an efficient remyelination of the adult brain. Since iron accumulation by OPCs is indispensable for myelination, understanding the iron incorporation mechanism as well as the molecules involved is critical to design new therapeutic approaches to intervene in diseases in which the myelin sheath is damaged or lost.

\section{Introduction}

In rodents, myelination takes place during early postnatal life. This process requires that oligodendrocyte precursor cells (OPCs)

Received June 7, 2018; revised Aug. 8, 2018; accepted Aug. 27, 2018.

Author contributions: V.T.C., D.A.S.G., L.N.M., M.E.G., and P.M.P. designed research; V.T.C., D.A.S.G., L.N.M., N.N.Z., M.E.G., V.S., and P.M.P. performed research;V.T.C., D.A.S.G., L.N.M., N.N.Z., M.E.G., V.S., and P.M.P. analyzed data; V.T.C., J.M.P. and P.M.P. wrote the paper.

This research was supported by the National Institute of Neurological Disorders and Stroke (Grant R01-NS-07804) and startup package from the Jacobs School of Medicine and Biomedical Sciences, University at Buffalo.

*V.T.C., D.A.S.G., and L.N.M. made equivalent contributions.

The authors declare no competing financial interests.

Correspondence should be addressed to Pablo M. Paez, Hunter James Kelly Research Institute, Department of Pharmacology and Toxicology, Jacobs School of Medicine and Biomedical Sciences, SUNY at Buffalo, NYS Center of Excellence, 701 Ellicott Street, Buffalo, NY 14203. E-mail: ppaez@buffalo.edu. experiment phenotypic changes to accomplish a maturation program that finally yields mature myelinating oligodendrocytes (OLs). Iron is an essential trophic factor that is required for oxygen consumption and ATP production. Thus, it plays a key role in vital cell functions. Experiments in primary cultures of OPCs show that iron can regulate OL proliferation and differentiation (Morath and Mayer-Pröschel, 2001). The importance of iron in myelin production and maintenance has been demonstrated by several studies showing that decreased availability of iron in the diet is associated with hypomyelination in animal models as well 
as in humans (Larkin and Rao, 1990; Connor, 1994; Roncagliolo et al., 1998; Algarín et al., 2003; Beard et al., 2003; Ortiz et al., 2004). For example, postnatal iron deficiency in rats significantly alters the production and composition of myelin (Ortiz et al., 2004; Badaracco et al., 2008) and strongly affects OL maturation (Rosato-Siri et al., 2010). In humans, the most common neurological signs of iron deficiency include decreased cognitive abilities and behavior problems (Grantham-McGregor and Ani, 2001). Several studies have shown that these clinical outcomes in iron-deficient humans can be traced to hypomyelination (Oski et al., 1983). Importantly, these neurological sequelae persist even after iron supplementation (Beard, 2007).

Iron accumulation by OLs is an early event in the development of these cells; however, how OPCs incorporate and store iron is not completely understood. Hill and Switzer (1984) demonstrated that physiological iron accumulation occurs in the CNS almost exclusively in OLs and thus OLs stained for iron more robustly that any other cell in the normal adult brain (Benkovic and Connor, 1993; Connor and Menzies, 1995; Connor et al., 1995). In iron-enriched brain areas such as the cerebellar nuclei and the striatum, the principal cells that stain for iron are OLs (Dwork et al., 1988; Benkovic and Connor, 1993; Todorich et al., 2009).

The divalent metal transporter 1 (DMT1) is an $\mathrm{H}^{+}$-driven metal transporter with a principal role in iron transport, and is responsible for iron uptake from the gut and transport from endosomes (Gruenheid et al., 1995; Veuthey and Wessling-Resnick, 2014). Although DMT1 has been previously described in the CNS, nothing is known about the function of DMT1 in OL maturation and myelination (Rouault, 2013). In the brain, DMT1 expression was found in neurons in the striatum, cerebellum, and thalamus (Skjørringe et al., 2015). The staining in the ependymal cells and endothelial cells suggests that DMT1 has an important role in iron transport into the brain (Skjørringe et al., 2015). DMT1 is also highly expressed by astrocytes in vitro as well as in vivo (Erikson and Aschner, 2006; Song et al., 2007), by microglial cells (Zhang et al., 2014) and by Schwann cells in the peripheral nervous system (Vivot et al., 2013). Likewise, DMT1 was found in OLs and the staining pattern was similar to transferrin in the subcortical white matter (Burdo et al., 2001). This staining pattern was consistent with in situ hybridization studies indicating that DMT1 is expressed by OLs in the white matter of adult rats (Burdo et al., 2001). Since iron is essential for brain metabolic processes, elucidating the mechanisms of OL iron metabolism is critical for understanding the role of iron in brain development, and particularly in myelination. Results from this study indicate that DMT1 is essential for OL maturation and myelination. We showed that DMT1 knockdown/knockout $(\mathrm{KO})$ reduces iron uptake and prevents OPC maturation and myelin production in vitro as well as in vivo.

\section{Materials and Methods}

Transgenic mice. All animals used in the present study were housed in the UB Division of Laboratory Animal Medicine vivarium, and procedures were approved by UB's Animal Care and Use Committee, and conducted in accordance with the guidelines in "Guide for the Care and Use of Laboratory Animals" from the National Institutes of Health. The heterozygous floxed DMT1 mice (catalog \#017789; RRID:IMSR_JAX: 017789) and the NG2CreER transgenic line $\mathrm{Tg}\left(\mathrm{Cspg} 4\right.$-cre/Esr $\left.1^{\star}\right)$ BAkik (catalog\#008538; RRID:IMSR_JAX:008538) were obtained from the The Jackson Laboratory. The Sox $10 \mathrm{CreER}{ }^{\mathrm{T} 2}$ transgenic mouse was obtained from Dr. Pachnis V. (University College London, London, UK) and was maintained as heterozygous (Laranjeira et al., 2011; Tripathi et al., 2011). Experimental animals were generated in our laboratory by crossing the
Table 1. siRNA target sequences used for DMT1 knockdown

\begin{tabular}{ll}
\hline & siRNA target sequences for mouse S/c11a2 \\
\hline siRNA1 & AGACAGGUGAAUCGGGCCA \\
siRNA2 & ACAAAUAUGGCUUGCGGAA \\
siRNA3 & GGACCUUUCUGACGAUGAA \\
SiRNA4 & GGUUUAAAGUGUAUCGAUA \\
\hline
\end{tabular}

heterozygous floxed DMT1 line with the hemizygous NG2CreER or Sox $10 \mathrm{Cre} \mathrm{ER}^{\mathrm{T} 2}$ transgenic lines. For all the experiments presented in this work, mice of either sex were used.

Mice treatments. To delete DMT1 in NG2-positive OPCs, Cre activity was induced starting at postnatal day 10 (P10). P10 NG2-DMT1 ${ }^{\text {KO }}$ $\left(\mathrm{DMT}_{1}{ }^{\mathrm{f} / \mathrm{f}}, \mathrm{NG} 2 \mathrm{Cr} e^{\mathrm{Cre} /-}\right)$ and control (Cre-negative) littermates (DMT1 ${ }^{\mathrm{f} / \mathrm{f}}$, $\mathrm{NG} 2 \mathrm{Cr}^{-1-}$ ) were intraperitoneally injected once a day for 5 consecutive days with $50 \mathrm{mg} / \mathrm{kg}$ tamoxifen (Sigma-Aldrich), and brain tissue was collected at P30 and P60. To delete DMT1 in Sox10-positive OPCs, P2 Sox10$\mathrm{DMT}^{\mathrm{KO}}\left(\mathrm{DMT}^{\mathrm{f} / \mathrm{f}}\right.$, Sox $\left.10 \mathrm{Cr} e^{\mathrm{Cre} /-}\right)$ and control (Cre negative) littermates $\left(\mathrm{DMT}_{1}{ }^{\mathrm{f} / \mathrm{f}}\right.$, Sox10Cre $\left.{ }^{-/-}\right)$were injected intraperitoneally once a day for 5 consecutive days with $25 \mathrm{mg} / \mathrm{kg}$ tamoxifen, and brain tissue was collected at P15 and P30. Furthermore, P60 Sox10-DMT1 ${ }^{\mathrm{KO}}$ and control littermates were injected intraperitoneally once a day for 5 consecutive days with $100 \mathrm{mg} / \mathrm{kg}$ tamoxifen, and brain tissue was collected at P90. A $20 \mathrm{mg} / \mathrm{ml}$ tamoxifen stock solution was prepared by dissolving and sonicating tamoxifen in 19:1 autoclaved vegetable oil/ethanol. We have found that five consecutive tamoxifen injections starting at $\mathrm{P} 2$ in mice double transgenic for Sox $10 \mathrm{CreER} \mathrm{ER}^{\mathrm{T} 2}$ and the Cre reporter B6.Cg-Gt(ROSA)26Sortm9(CAG-tdTomato)Hze/J (catalog \#007909, The Jackson Laboratory; RRID:IMSR_JAX:007909) revealed recombination activity in $>90 \%$ of callosal and cortical OL transcription factor 2 (Olig2)positive cells at P15 and P30 (data not shown). In this mouse line, $25 \mathrm{mg} / \mathrm{kg}$ tamoxifen per injection was the highest nontoxic dose for P2 pups. On the other hand, the maximum level of recombination in the NG2CreER line ( $\sim 80 \%$ of Olig2-positive cells) was achieved injecting P10 animals with five consecutive tamoxifen injections of $50 \mathrm{mg} / \mathrm{kg}$ (Cheli et al., 2016). For remyelination studies, P60 NG2-DMT1 ${ }^{\mathrm{KO}}\left(\mathrm{DMT} 1^{\mathrm{f} / \mathrm{f}}, \mathrm{NG} 2 \mathrm{Cr} e^{\mathrm{Cre} /-}\right)$ and control (Cre negative) littermates (DMT1 ${ }^{\mathrm{f} / \mathrm{f}}, \mathrm{NG} 2 \mathrm{Cre}^{-/-}$) were fed pellet chow containing $0.2 \%$ cuprizone (CPZ; Teklad-Envigo) for 7 weeks and were injected with $100 \mathrm{mg} / \mathrm{kg}$ tamoxifen every other day during the last week of the cuprizone treatment and through the first week of recovery as was described in the study by Santiago González et al. (2017). Additionally, a group of control (DMT1 $\left.{ }^{\mathrm{f} / \mathrm{f}}, \mathrm{NG} 2 \mathrm{Cre}^{-/-}\right)$mice was maintained on a diet of normal pellet chow.

Primary cultures of cortical OPCs. Primary cultures of cortical OPCs were prepared as described by Amur-Umarjee et al. (1993). First, cerebral hemispheres from 1-d-old mice were mechanically dissociated and were plated on poly-D-lysine-coated flasks in DMEM/F12 (1:1, v/v; Invitrogen), supplemented with $10 \%$ fetal bovine serum (FBS; Life Technologies). After $4 \mathrm{~h}$, the medium was changed, and the cells were grown in DMEM/F12 supplemented with insulin $(5 \mu \mathrm{g} / \mathrm{ml})$, apo-transferrin (Tf; $50 \mu \mathrm{g} / \mathrm{ml}$ ), sodium selenite (30 nM), D-Biotin (10 mM), and 10\% FBS (Life Technologies). Two-thirds of the culture media was changed every $3 \mathrm{~d}$. After $14 \mathrm{~d}$, OPCs were purified from the mixed glial culture by the differential shaking and adhesion procedure of Suzumura et al. (1984) and allowed to grow on poly-D-lysine-coated coverslips in DMEM/F12 supplemented with insulin $(5 \mu \mathrm{g} / \mathrm{ml})$, apo-transferrin $(50 \mu \mathrm{g} / \mathrm{ml})$, sodium selenite (30 nM), 0.1\% BSA, progesterone $(0.06 \mathrm{ng} / \mathrm{ml})$, and putrescine (16 $\mu \mathrm{g} / \mathrm{ml}$; Sigma-Aldrich). OPCs were kept in mitogens, PDGF and bFGF (20 ng/ml; Peprotech), for $2 \mathrm{~d}$ and then induced to differentiate by mitogen withdrawal and T3 (15 nM) addition. Because of the inherent variability in cell growth from culture to culture, quadruplicate cultures were prepared. Since the size of the litter significantly affects the development of a pup, litters with $<5$ or $>10$ pups were not used.

small interfering RNA knockdown of DMT1. OPCs were transiently transfected with a combination of four different small interfering RNA (siRNA) duplexes (ON-TARGETplus SMARTpool siRNAs, Thermo Fisher Scientific) specific for DMT1 (Table 1, siRNA target sequences). Briefly, 6 pmol of each siRNA duplex were mixed with Lipofectamine 
Table 2. Sequences of primers used for RT-PCR

\begin{tabular}{llll}
\hline & Forward & Reverse & PCR fragment (bp) \\
\hline DMT1A & 5'-GTACTCCTCTGCATATATAGAGG & 5'-CTAGGTAGGCAATGCTCATAAGAAAGCCAGG & 405 \\
DMT1B & 5'-CAATCACGGGAGGGCAGGAG & 5'-CTAGGTAGGCAATGCTCATAAGAAAGCCAGG & 385 \\
DMT1 + IRE & 5'-CTGCTGAGGGAGATACCAG & 5'-CTCAGGAGCTTAGGTCAGAAG & 351 \\
DMT1 - IRE & 5'-CGCCCAGATTTACACAGTG & 5'-AAGCTTCACTACCTGCACAC & 350 \\
DMT1 floxed & 5'-CTCCCACATTCCACTGGAGAC & 5'-TGCTTCAGCAAAGAGGACA & WT 858 K0 612 \\
\hline
\end{tabular}

RNAiMAX (Life Technologies), and the mixture was added to $35 \mathrm{~mm}$ Petri dishes or coverslips containing $\sim 80 \%$ confluent OPCs $24 \mathrm{~h}$ after plating. After transfection, OPCs were further cultured for $24 \mathrm{~h}$ in defined culture media plus PDGF (20 ng/ml) and bFGF (20 ng/ml), and then the cells were switched to a mitogen-free medium to induce differentiation. Control cells were transfected with scrambled siRNAs, and some OPCs were treated with fluorescein-labeled dsRNA oligomers (BLOCK-iT Fluorescent Oligos, Life Technologies) to determine siRNA transfection efficiency.

Lentivirus-mediated Cre deletion of floxed DMT1. Primary cultures of cortical OPCs were prepared from homozygous floxed DMT1 mice, as described above. DMT1-floxed OPCs were infected with lentiviruses expressing both Cre recombinase and GFP and control lentiviruses expressing the RFP (Cellomics Technology). Lentivirus infections were performed $24 \mathrm{~h}$ after plating, 8 multiplicities of infection were added to 24 -well dishes containing $\sim 80 \%$ confluent OPCs. OLs were infected for $12 \mathrm{~h}$ with a reduced volume of culture medium containing the virus at the appropriate concentration. After infection, OPCs were further cultured for $24 \mathrm{~h}$ in defined culture media plus PDGF and bFGF (20 ng/ml), and then the cells were switched to a mitogen-free medium to induce differentiation.

Immunocytochemistry. Cells were stained with antibodies against several OL stage-specific markers following the protocol outlined in Cheli et al. (2016). Fluorescent images were obtained using a spinning disc confocal microscope (model IX83-DSU, Olympus). Quantitative analysis of the results was performed counting the antigen-positive and DAPIpositive cells (total number of cells) in 20 randomly selected fields per coverslip, which resulted in counts of $>2000$ cells. For all experimental conditions, four coverslips per culture were analyzed, and the data represent pooled results from at least four independent cultures. Cell counting was performed semiautomatically and blind to the genotype of the sample by MetaMorph software (Molecular Devices; RRID: SCR_002368). The primary antibodies used for immunocytochemistry were against the following: caspase-3 (mouse; 1:200; Cell Signaling Technology; RRID:AB_2341188); CC1 (mouse; 1:300; Calbiochem; RRID: AB_2057371); DMT1 (rabbit; 1:500; Abcam; RRID:AB_10971807); Ki67 (rabbit; 1:250; Abcam; RRID:AB_443209); Ki67 (mouse; 1:250; BD Biosciences; RRID:AB_396287); MBP (mouse; 1:1000; Covance; RRID: AB_510039); myelin OL glycoprotein (MOG; mouse; 1:200; Millipore; RRID:AB_1587278); NG2 (rabbit; 1:400; Millipore; RRID:AB_91789); Olig2 (mouse and rabbit; 1:500; Millipore; RRID:AB_570666 and RRID: AB_10807410, respectively); PDGF receptor (PDGFr; mouse; 1:200; Millipore; RRID:AB_2283679); phospho-histone H3 (rabbit; 1:500; Millipore; RRID:AB_310177); and Tf receptor 1 (Tfr1; mouse; 1:500; Life Technologies; RRID:AB_2533029).

Western blot. Protein samples were extracted using lysis buffer, as described in the study by Santiago González et al. (2017). Twenty micrograms of proteins were separated with Invitrogen Novex NuPAGE $4-12 \%$ Bis-Tris Protein Gels (Thermo Fisher Scientific) and electroblotted onto PDVF membranes. Membranes were blocked overnight at $4^{\circ} \mathrm{C}$ with $5 \%$ nonfat milk and $0.1 \%$ Tween-20 in PBS. Primary antibodies were diluted with the blocking solution, and membranes were incubated for $3 \mathrm{~h}$ at room temperature with agitation. Protein bands were detected by chemiluminescence using an ECL kit (GE Healthcare) with horseradish peroxidase-conjugated secondary antibodies (GE Healthcare; RRID:AB_772206 and RRID:AB_772210) and scanned with a C-Digit Bot Scanner (LI-COR). Protein bands were quantified using the Image Studio Software (LI-COR; RRID:SCR_014211). Data represent pooled results from at least six independent experiments.
The following primary antibodies were used: cyclic nucleotide phosphodiesterase (CNP; 1:1000; Neo-Markes; RRID:AB_61312); DMT1 (rabbit; 1:500; Abcam; RRID:AB_10971807); GAPDH (mouse; 1:10,000; Genetex; RRID:AB_11174761); MBP (mouse; 1:1000; Covance; RRID: AB_510039); MOG (mouse; 1:1000; Millipore; RRID:AB_1587278); and proteolipid protein (PLP; rat; 1:500; AA3-PLP/DM20, RRID:AB_2341144) and $\beta$-actin (mouse; 1:10,000; Sigma-Aldrich; RRID:AB_476744).

$R T-P C R$. Total RNA was isolated using TRIzol reagent (Thermo Fisher Scientific). RNA content was estimated by measuring the absorbance at $260 \mathrm{~nm}$, and the purity was assessed by measuring the ratio of absorbance: 260/280 nm. PCR primers for DMT1 isoforms were designed based on published sequences by Hubert and Hentze (2002; Table 2 for primer sequences). First-strand cDNA was prepared from $1 \mu \mathrm{g}$ of total RNA using SuperScript III RNase H Reverse Transcriptase (Thermo Fisher Scientific) and $1 \mu \mathrm{g}$ of oligo(dT). The mRNA samples were denaturized at $65^{\circ} \mathrm{C}$ for $5 \mathrm{~min}$. Reverse transcription was performed at $50^{\circ} \mathrm{C}$ for $55 \mathrm{~min}$ and was stopped by heating the samples at $85^{\circ} \mathrm{C}$ for $5 \mathrm{~min}$. The cDNA was amplified by PCR using the DMT1 isoform-specific primers and PCR Platinum Supermix Reagent (Thermo Fisher Scientific). PCR conditions were as follows: $94^{\circ} \mathrm{C}$ for $2 \mathrm{~min}, 40$ cycles of $94^{\circ} \mathrm{C}$ for $30 \mathrm{~s}$, and $58^{\circ} \mathrm{C}$ for $30 \mathrm{~s}$ followed by $72^{\circ} \mathrm{C}$ for $2 \mathrm{~min}$. After 40 cycles, samples were incubated at $72^{\circ} \mathrm{C}$ for $5 \mathrm{~min}$. The PCR products were visualized on an SYBR Safe-stained agarose gel, and the bands were digitized using a Gel Doc EZ System (Bio-Rad). Data represent pooled results from at least four independent experiments.

Colorimetric iron assay. The Quantichrom Iron Assay Kit (BioAssay Systems) was used to measure total cellular iron. Briefly, $50 \mu$ l of samples containing $1 \times 10^{6}$ cells were mixed with $200 \mu$ l of Quantichrom working reagent in a 96-well plate and were incubated at room temperature for $40 \mathrm{~min}$. The optical density (OD) at $590 \mathrm{~nm}$ was measured by a microplate reader. The OD against standard iron concentrations were plotted by subtracting blank (water) OD from the standard OD values, and the slope of the data plot then was determined using liner regression fitting. The total protein concentration was estimated using the Pierce BCA Protein Assay Kit (Thermo Fisher Scientific). Data represent pooled results from at least four independent experiments.

MTT assay. The MTT survival assay was performed as described by Mosmann (1983). The sterile solution of MTT (Thermo Fisher Scientific) was added to all wells, and the microplate was incubated at $37^{\circ} \mathrm{C}$ for $45 \mathrm{~min}$. The reaction was stopped by the addition of SDS, and the product was quantified by spectrophotometry at $570 \mathrm{~nm}$. Data represent pooled results from at least four independent experiments.

Immunohistochemistry. All animals were anesthetized with isoflurane and then perfused with $4 \%$ of paraformaldehyde in PBS via the left ventricle. The brains were postfixed overnight in the same fixative solution at $4^{\circ} \mathrm{C}$. Coronal brain slices that were $50 \mu \mathrm{m}$ thick were obtained using a vibratome (VT1000-S, Leica Biosystems). Free-floating vibratome sections were incubated in a blocking solution ( $2 \%$ normal goat serum and $1 \%$ Triton X-100 in PBS) for $2 \mathrm{~h}$ at room temperature and then were incubated with the primary antibody overnight at $4^{\circ} \mathrm{C}$. Sections were then rinsed in PBS and incubated with Cy3- or Cy5-conjugated secondary antibodies (1:400; Jackson ImmunoResearch) for $2 \mathrm{~h}$ at room temperature followed by a counterstain with the nuclear dye DAPI (Thermo Fisher Scientific). After washing, the sections were mounted on to Superfrost Plus Slides (Thermo Fisher Scientific) using coverslips and mounting medium (Aquamount; Thermo Fisher Scientific). The primary antibodies used in the present study were against the following: caspase-3 (mouse; 1:200; Cell Signaling Technology; RRID:AB_2341188); CC1 (mouse; 1:300; Calbiochem; RRID:AB_2057371); Ki67 (rabbit; 1:250; 
Abcam; RRID:AB_443209); Ki67 (mouse; 1:250; BD Biosciences; RRID: AB_396287); MBP (mouse; 1:1000; Covance; RRID:AB_510039); MOG (mouse; 1:200; Millipore; RRID:AB_1587278); Olig1 (mouse; 1:500; Millipore; RRID:AB_92198); Olig2 (mouse and rabbit; 1:500; Millipore; RRID:AB_570666 and RRID:AB_10807410); PLP (rat; 1:50; AA3-PLP/ DM20; RRID:AB_2341144); and Sox2 (rabbit; 1:200; Millipore; RRID:AB_2286686).

The staining intensity for myelin proteins as well as the number of positive cells was assessed in the central area of the corpus callosum, between the midline and below the apex of the cingulum $\left(0.6 \mathrm{~mm}^{2}\right)$, in the motor and cingulate cortex, including the motor cortex (M1), M2, Cg1, and Cg2 (0.6 $\mathrm{mm}^{2}$; Franklin and Paxinos, 2008, their Fig. 24), and in the dorsal/caudal striatum, immediately underneath the corpus callosum $\left(0.6 \mathrm{~mm}^{2}\right)$. The integrated fluorescence intensity was calculated as the product of the area and mean pixel intensity using MetaMorph software (Molecular Devices; RRID:SCR_002368). For all experiments involving the quantification of positive cells and fluorescent intensity in tissue sections, data represent pooled results from at least six brains per experimental group. Seven slices per brain ( $50 \mu \mathrm{m}$ each) were used, and quantification was performed blind to the genotype of the sample using an unbiased stereological sampling method.

Black-Gold II myelin staining. Black Gold II staining was performed as described by Cheli et al. (2016). Briefly, paraformaldehyde-fixed brain sections of $50 \mu \mathrm{m}$ were mounted onto Superfrost Plus slide (Thermo Fisher Scientific). Coronal brain slices were initially air dried and then rehydrated and transferred to a lukewarm 0.3\% Black Gold II solution (Millipore). After color development ( $\sim 10 \mathrm{~min})$, the slides were rinsed with a $1 \%$ sodium thiosulfate solution at $60^{\circ} \mathrm{C}$, dehydrated, and mounted with Permount. The integrated staining intensity in the corpus callosum, striatum, and cortex was assessed by MetaMorph Software (Molecular Devices; RRID:SCR_002368). The staining intensity in control mice was given the arbitrary value of 100 , and the staining intensity in DMT1 ${ }^{\mathrm{KO}}$ mice was determined as a percentage of that in control mice. Seven slices per brain were used, and the data represent pooled results from at least six brains per experimental group.

Perl's histochemistry. Enhanced Perl's histochemistry was performed as described previously by Meguro et al. (2007) with slight variations. Briefly, $20 \mu \mathrm{m}$ coronal brain sections were incubated with $1 \% \mathrm{H}_{2} \mathrm{O}_{2}$ in methanol for $15 \mathrm{~min}$ and then with $2 \%$ potassium ferrocyanide, $\mathrm{pH} 1.0$, overnight (Iron Stain Kit, Sigma-Aldrich). The reaction was enhanced for 30 min with $0.025 \%$ 3,3'-diaminobenzidine- $4 \mathrm{Hl}, 0.05 \% \mathrm{H}_{2} \mathrm{O}_{2}$, and $0.005 \% \mathrm{CoCl}_{2}$ in $0.1 \mathrm{M} \mathrm{PB}$. Finally, sections were dehydrated and mounted with Permount. The number of positive OLs and the integrated staining intensity per cell was assessed by MetaMorph software (Molecular Devices; RRID:SCR_002368) in the central area of the corpus callosum, between the midline and below the apex of the cingulum $\left(0.6 \mathrm{~mm}^{2}\right)$ and in the motor and cingulate cortex including M1, M2, Cg1, and Cg2 $\left(0.6 \mathrm{~mm}^{2}\right.$; Franklin and Paxinos, 2008, their Fig. 24). Moreover, the integrated staining intensity in neurons was assessed in the M1, including all cortical layers (Franklin and Paxinos, 2008, their Fig. 24), in the globus pallidus (Franklin and Paxinos, 2008, their Fig. 42), and in the substantia nigra (Franklin and Paxinos, 2008, their Fig. 52). Seven slices per brain were used, and data represent pooled results from at least six brains per experimental group.

Electron microscopy. Mouse brains were perfused transcardially with $3 \%$ paraformaldehyde and $1 \%$ glutaraldehyde. The body of the corpus callosum at the anterior-dorsal level of the hippocampus was dissected and resin was embedded. Thin sections were stained with uranyl acetate and lead citrate, and photographed with an FEI Tecnai F20 Transmission Electron Microscope (Thermo Fisher Scientific), as previously described (Cheli et al., 2016). For g-ratio (ratio of the inner axonal diameter to the total outer diameter) measurements, at least 150 fibers per animal were analyzed. The percentage of myelinated axons was determined in 10 randomly selected fields per sample, which resulted in counts of $>1000$ axons. The g-ratio and the percentage of myelinated axons were determined semiautomatically and were blind to the genotype of the sample using MetaMorph Software (Molecular Devices; RRID:SCR_002368). For all experimental conditions, data represent pooled results from at least four mice.
Experimental design and statistical analysis. All datasets were tested for normal distribution using Kolmogorov-Smirnov tests. Single betweengroup comparisons were made by the unpaired $t$ test (Student's $t$ test), using a confidence interval of $95 \%$. Multiple comparisons were investigated by one-way ANOVA followed by Bonferroni's multiplecomparison tests to detect pairwise between-group differences. For the analysis of g-ratio scatter plots, simple linear regression with a confidence interval of $95 \%$ was used. All statistical tests were performed in GraphPad Prism (GraphPad Software; RRID:SCR_002798). A fixed value of $p<$ 0.05 for a one-tailed test was the criterion for reliable differences between groups. Data are presented as the mean \pm SEM. No data points were excluded from this study. To minimize bias, the quantification and analysis of all the experiments described in this work were performed by two independent investigators, who were both blinded to the sample genotype. The genotype of the sample was coded and determined by a technician, who provided the genotype after the statistical analysis was complete. Based on previous studies, power calculations, and the fact that all comparisons were made between animals with the same genetic background, we compare at least six mice for each genotype for all the morphological and biochemical endpoints. To date, we have not encountered any difference in OL development, myelination, or remyelination attributable to mouse gender, and thus both sexes were used. Details regarding the number of cells, the specific brain areas and the number of brain slices analyzed can be found in the individual assay descriptions. Complete results of the statistical analyses, including exact $p$ values are included in the figure legends.

\section{Results \\ DMT1 is upregulated during OL maturation in vitro}

Initially, we examined the expression of DMT1 in cultured OLs at different developmental stages. OPCs were obtained from the brain cortices of P1-P2 mice and were kept under proliferative conditions in the presence of PDGF and bFGF. After $2 \mathrm{~d}$ in vitro (DIV), OPCs were induced to exit from the cell cycle and differentiate by switching the cells to a mitogen-free medium and the addition of T3 (Fig. 1A). To analyze DMT1 expression in OPCs and mature OLs, RT-PCR experiments using DMT1-specific primers were performed at 2 and 4 DIV. Four DMT1 isoforms, were reported in mammals, this includes two $\mathrm{N}$-terminal variants having alternative exon 1 (exons 1A and 1B; Hubert and Hentze, 2002) and two C-terminal alternatives with and without an ironresponsive element (IRE; Fleming et al., 1998; Lee et al., 1998). We found that only DMT1B was present in cortical OLs; DMT1A was not detected in either immature or mature OLs (Fig. 1B). Moreover, only mature OLs transcribe DMT1 mRNAs containing an IRE (Fig. 1B). Furthermore, Western blot experiments showed that DMT1 synthesis increases dramatically when OPCs are induced to mature by growth factor withdrawal and the addition of T3 (Fig. 1C). Using confocal analysis, we found DMT1 expression throughout the cell body, nucleus, and processes of OPCs cultivated for 2 DIV in the presence of PDGF and bFGF (Fig. 1D). DMT1 fluorescence was predominantly concentrated in the cell nucleus and in multiple high-intensity patches along the cell processes where it colocalized partially with the Tfr (Fig. 1D).

\section{DMT1 knockdown/knockout delays OL maturation in vitro} To assess the role of DMT1 on OPC differentiation, we knocked down the expression of DMT1 in primary cultures of cortical OPCs. OPCs were transfected with a combination of four different small interfering RNA duplexes specific for DMT1 (siDMT1). siRNAs were selected to target four distinct DMT1 mRNA regions to enhance silencing (Table 1). Scrambled siRNAs were used for sequence-independent effects in all the siRNA experiments performed. To determine transfection efficiency, OPCs 
A

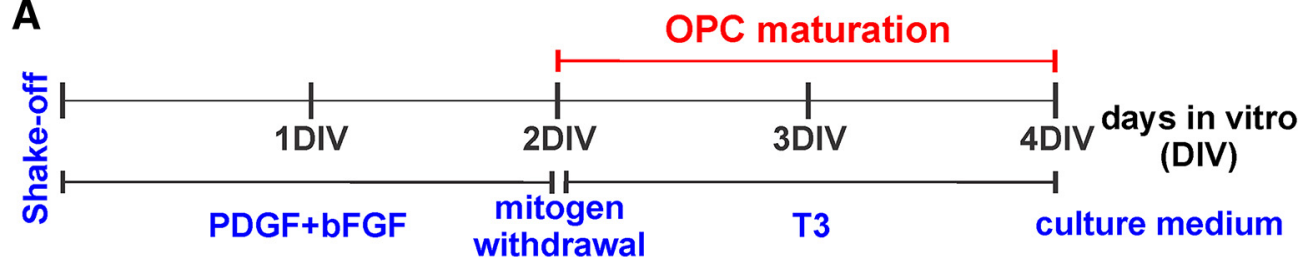

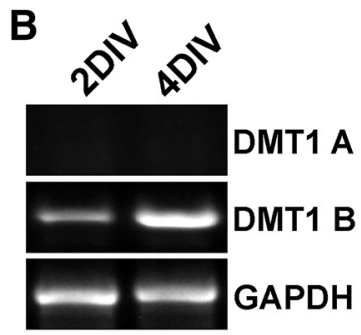

mRNA

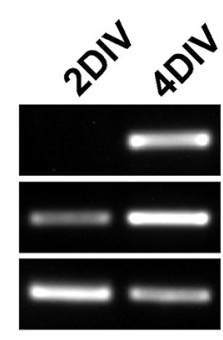

mRNA
C

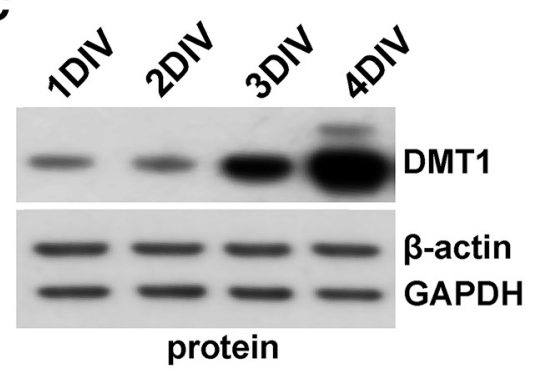

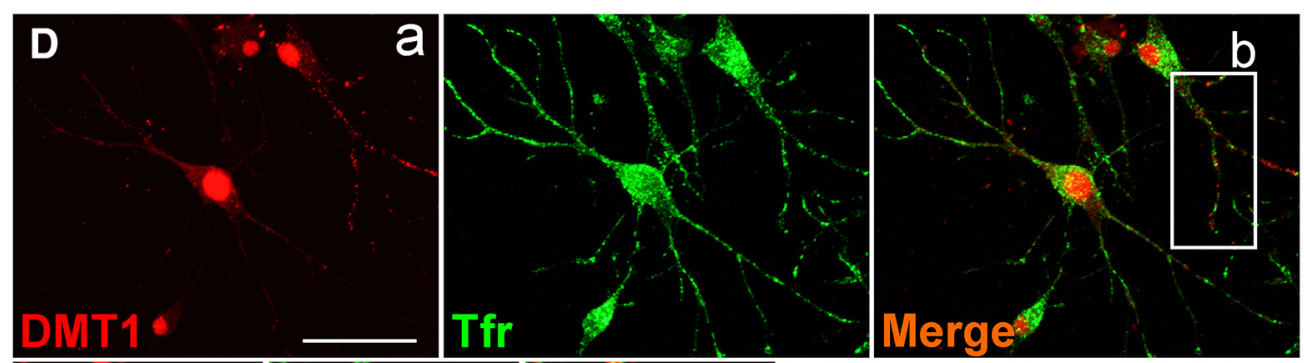

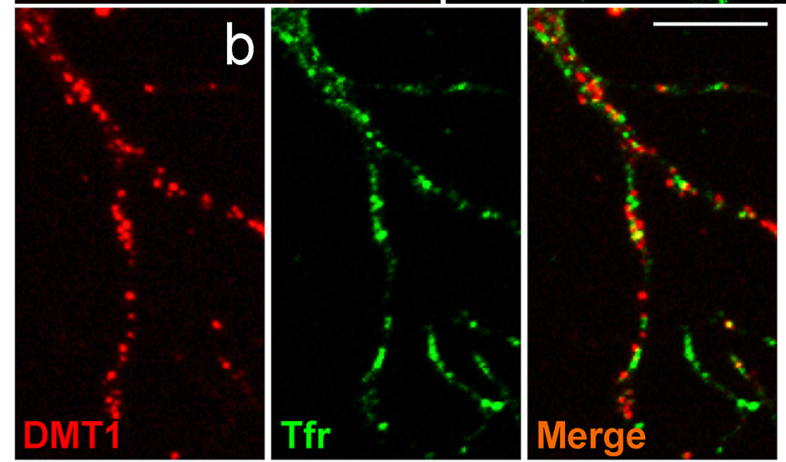

Figure 1. DMT1 expression in cultured OLS. A, OPCS were cultured for 2 DIV in defined culture media plus PDGF and bFGF and then induced to mature by mitogen removal and T3 addition. $B$, RT-PCR analysis of DMT1 expression at 2 and 4 DIV. Specific primers were designed to identify DMT1 isoforms $A$ and $B$ and DMT1 mRNAs with and without an IRE (Table 2); GAPDH was used as internal standard. C, Western blot study of DMT1 at different time-points in vitro, $\beta$-actin and GAPDH were used as internal standards. D, OPCs were costained with antibodies against DMT1 and the Tfr at 2 DIV. Higher-magnification pictures of the boxed area in $\boldsymbol{a}$ are showed in $\boldsymbol{b}$. Scale bars: $\boldsymbol{a}, 40 \mu \mathrm{m} ; \boldsymbol{b}, 20 \mu \mathrm{m}$.

were treated with fluorescein-labeled dsRNA oligomers. We found that $>90 \%$ of the OPCs displayed siRNA fluorescent signals at different time-points after transfection (Fig. 2A). Figure $2 B$ shows a representative RT-PCR and Western blot demonstrating that DMT1 siRNA decreased DMT1 mRNAs and proteins in OPCs $3 \mathrm{~d}$ after transfection. Figure $2 E$ shows the effect of DMT1 siRNAs on OPC iron uptake. As time passes in culture, control cells showed a continuous increase in iron accumulation, which correlates with the expression of DMT1 in these cells (Fig. $2 E)$. No differences between genotypes were found at 1 or 2 DIV, but during the maturation phase of our culture protocol ( 3 and 4 DIV) siDMT1 transfected OPCs displayed lower iron acquisition than control cells (Fig. 2E).

After mitogen removal, our data show that the morphological differentiation as well as the expression of mature OL markers was significantly inhibited in DMT1-deficient OPCs (Fig. $2 C, D, F)$. Two days after mitogen withdrawal, DMT1 siRNAs induced a decrease in the percentage of OLs expressing myelin proteins such as MOG and MBP, and an increase in the number of immature OPCs positive for NG2 and PDGF receptor $\alpha$ (Fig. $2 C, D)$. In addition, the percentage of positive cells for the mature OL marker CC1 was significantly reduced in siDMT1-transfected cultures (Fig. 2C,D). Furthermore, the average number of proliferating cells (Ki67 and phospho-histone-H3-positive cells) in the siDMT1-transfected cultures was significantly higher than that of the control group (Fig. 2C,D). OL morphology was also evaluated $3 \mathrm{~d}$ after siDMT1 transfection. Individual MBP-positive cells were scored according to their morphological complexity in four different categories, according to the number of primary and secondary processes, the presence of MBP-positive sheets, and the total size of the cell (Sperber and McMorris, 2001). Suggesting a delay in OPC morphological maturation, a significant decrease in the percentage of cells with medium, medium-high, and high morphology, and a sharp increase in the percentage of cells with 
A

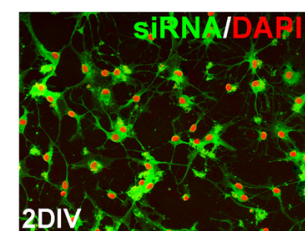

C

Control
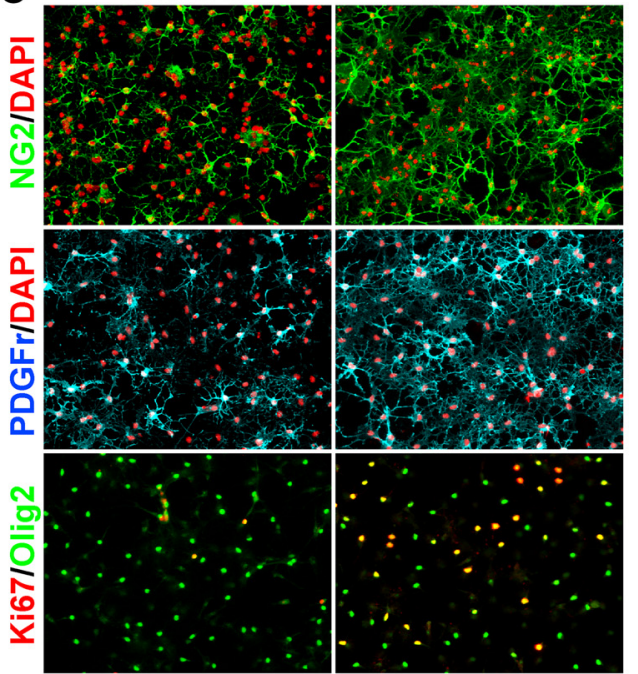

D

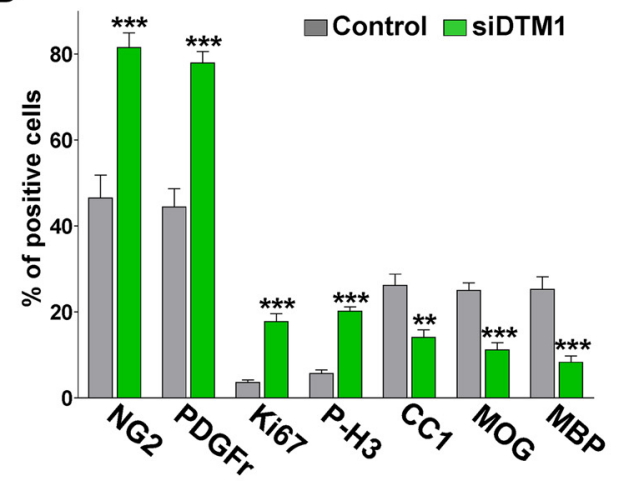

$\mathbf{F}$

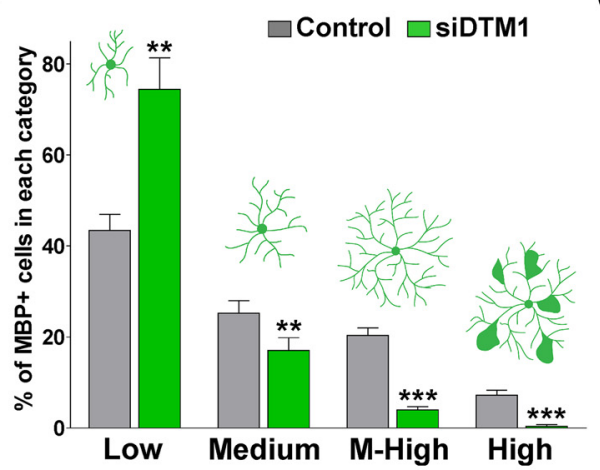

B
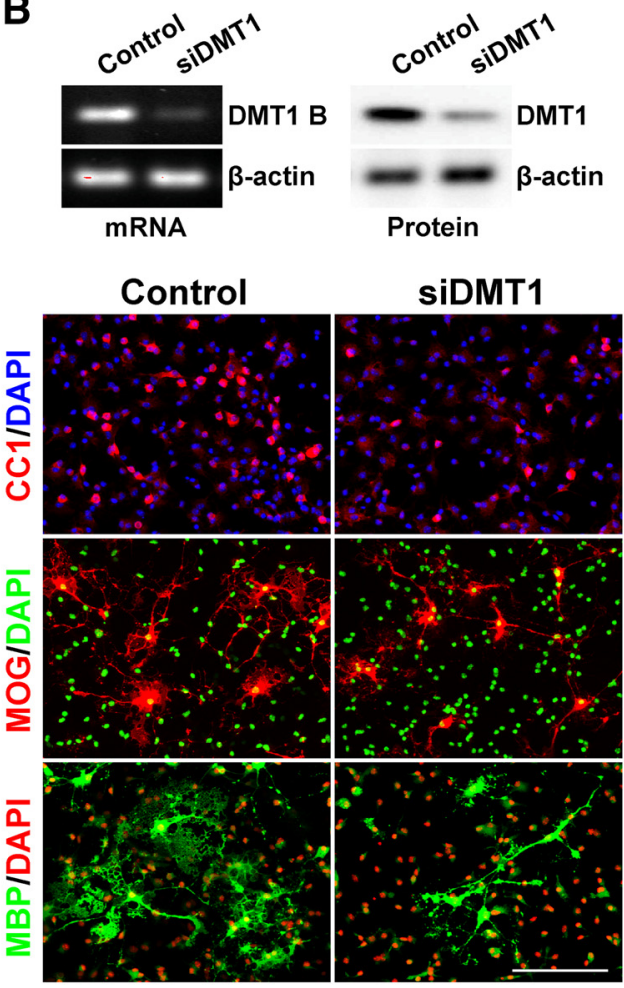

E
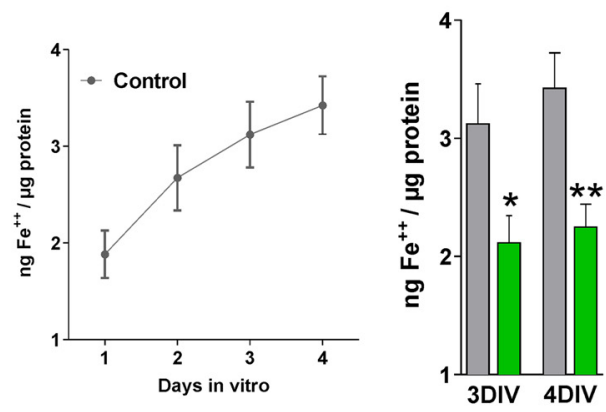

G

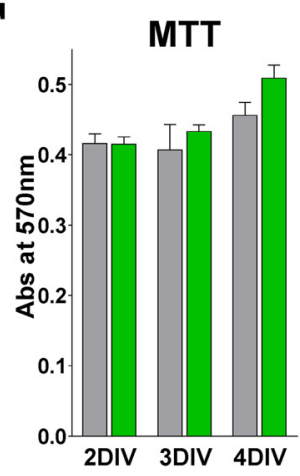

H

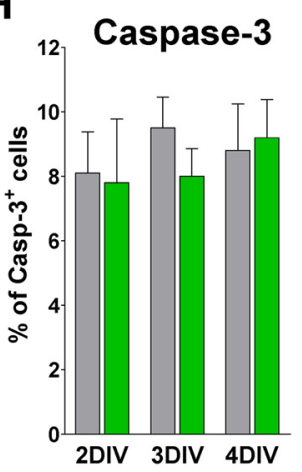

Figure 2. DMT1 knockdown blocks OPC maturation. OPCs were transfected with four siDMT1s and grown as described in Figure 1.A,OPCs were treated with fluorescein-labeled dsRNA oligomers to determine siRNA transfection efficiency. $\boldsymbol{B}$, Three days after siRNA transfection, semiquantitative RT-PCR and Western blot analysis of DMT1 expression in OPCs was performed using $\beta$-actin as an internal standard. C, D, Three days after siDMT1 transfection, OPCs were stained with antibodies against NG2, PDGFr, Ki67, P-Histone H3, CC1, MOG, and MBP, and the percentage of positive cells in each experimental condition was examined by confocal microscopy. Exact $p$ values from left to right: $<0.0001 ;<0.0001 ;<0.0001 ;<0.0001 ; 0.0012 ;<0.0001 ;<0.0001$. Scale bar, $80 \mu \mathrm{m}$. $\boldsymbol{E}$, Total iron content was examined in control and siDMT1-transfected OPCs using a colorimetric iron assay. Exact $p$ values: 3 DIV, 0.0246; 4 DIV, 0.0049 . F, Morphological complexity of MBP-positive cells was scored in four categories. Exact $p$ values from left to right: $0.0042 ; 0.0073 ;<0.0001 ; 0.0005$. G, Evaluation of OPCs viability and the proliferation by the MTT assay at different time-points after siDMT1 transfection. Exact $p$ values from left to right: $0.9547 ; 0.4954 ; 0.0570$. H, OPC death was evaluated by measuring the percentage of caspase-3-positive cells in each experimental group. Exact $p$ values from left to right: $0.9004 ; 0.2581 ; 0.8332$. Comparisons between experimental groups were made by the unpaired $t$ test. Values are expressed as the mean \pm SEM of four independent experiments. ${ }^{*} p<0.05,{ }^{* *} p<0.01,{ }^{* * *} p<0.001$ vs respective controls. 
A

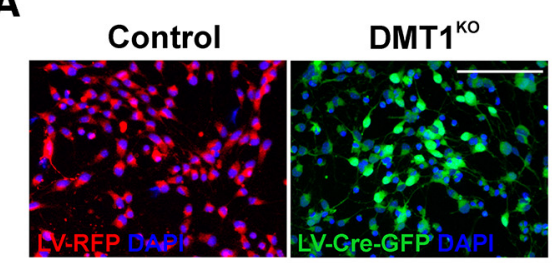

C
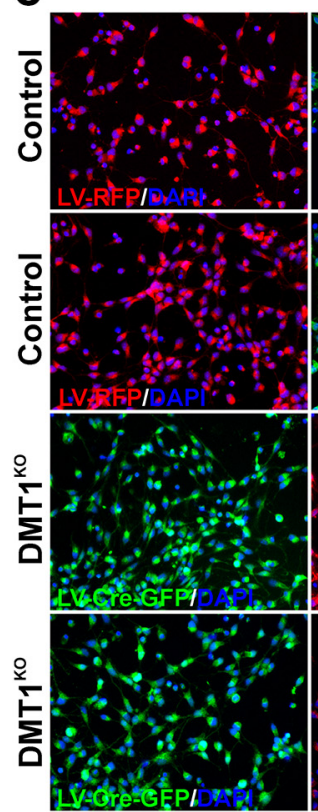

B

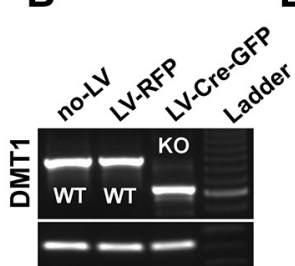

GAPDH
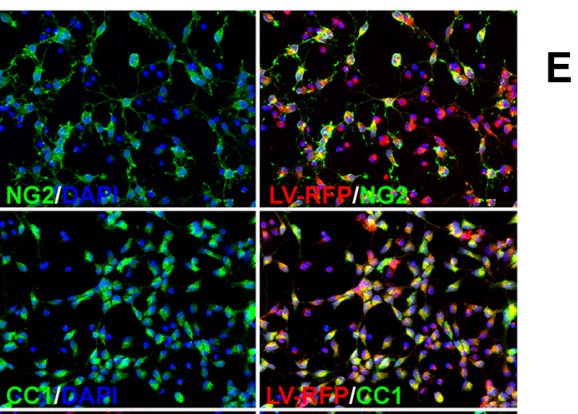

$\mathbf{E}$
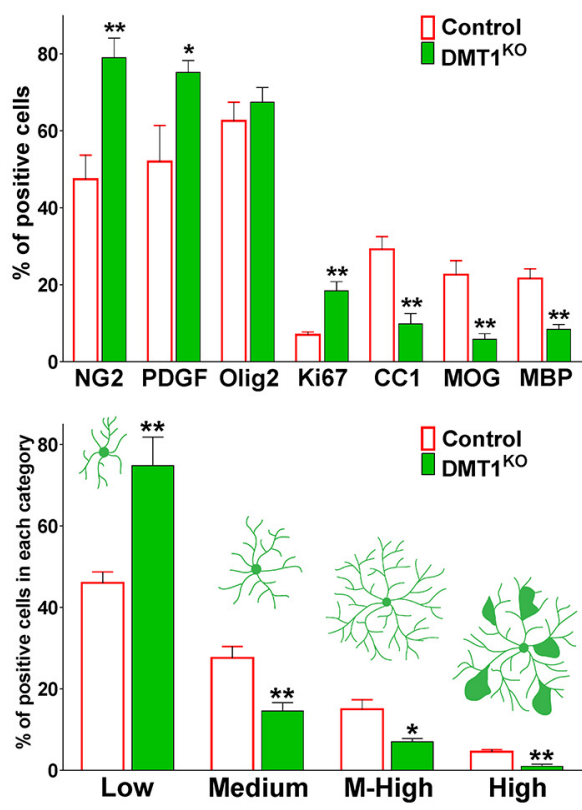

$F$
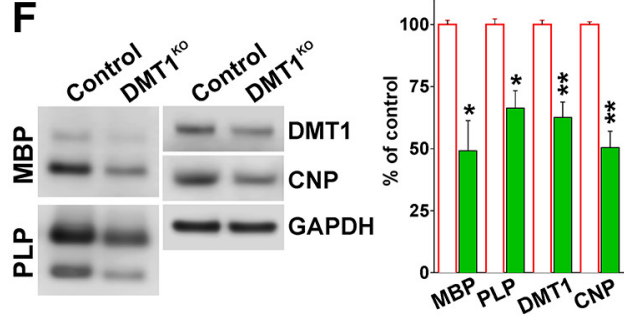

Figure 3. DMT1 KO OPCs do not mature normally. A, DMT1-floxed OPCs were infected with lentiviruses expressing both Cre recombinase and GFP (LV-Cre-GFP), and control lentiviruses expressing the RFP (LV-RFP). $\boldsymbol{B}$, Three days after infection, RT-PCR analysis of DMT1 expression in OPCs was performed using GAPDH as an internal standard. $\boldsymbol{C}, \boldsymbol{D}$, Three days after infection, control (LV-RFP) and $\mathrm{DMT1}^{\mathrm{K} 0}$ (LV-Cre-GFP) OPCs were stained with antibodies against NG2, PDGFr, 0lig2, Ki67, CC1, M0G, and MBP, and the percentage of positive cells in each experimental condition was examined by confocal microscopy. Exact $p$ values from left to right: $0.0046 ; 0.0464 ; 0.4581 ; 0.0018 ; 0.0014 ; 0.0028 ; 0.0017$. Scale bar, $80 \mu \mathrm{m}$. $\boldsymbol{E}$, Morphological complexity of control (LV-RFP) and DMT1 K0 (LV-Cre-GFP) cells was scored in four categories. Exact $p$ values from left to right: $0.0050 ; 0.0058 ; 0.0119 ; 0.0013$. $\boldsymbol{F}$, Three days after lentivirus infection, total proteins were collected from primary OPC cultures to assess the expression of myelin proteins by Western blot. GAPDH was used as an internal standard, and data from four independent experiments are summarized based on the relative spot intensities. Exact $p$ values from left to right: $0.0420 ; 0.0121 ; 0.0046 ; 0.0016$. Comparisons between experimental groups were made by the unpaired $t$ test. Values are expressed as the mean \pm SEM of four independent experiments. ${ }^{*} p<0.05,{ }^{* *} p<0.01,{ }^{* * *} p<0.001$ vs respective controls.

low complexity were found in siDMT1-transfected cultures (Fig. $2 F$ ). Importantly, no changes in OPC metabolic activity due to variations in cell viability/proliferation (MTT assay) or apoptotic cell death (caspase-3-positive cells) were detected (Fig. 2G,H).

Similar results were found in primary cultures of DMT1floxed OPCs infected with lentivirus expressing Cre-recombinase (Fig. 3). In the floxed mutant DMT1 line (Gunshin et al., 2005; Carlson et al., 2009), exons 6 to 8 of the wild-type DMT1 gene (Slc11a2) were flanked with loxP sites, and, thus, exons $6-8$ are eliminated when $\mathrm{Cre}$-recombinase is present. The removal of exons 6-8 leads to a truncated, nonfunctional DMT1 protein (Gunshin et al., 2005; Carlson et al., 2009). Homozygous DMT1-floxed OPCs were infected with lentiviruses expressing Cre-recombinase and GFP (LV-Cre-GFP) as well as control lentiviruses expressing only the RFP (LV-RFP). Three days after infection, $>95 \%$ of the cells were positive for GFP or RFP (Fig. $3 A$ ), and RT-PCR experiments showed high recombination efficiency in Cre-expressing OLs (Fig. 3B). In agreement with the siRNA knock-down experiments, DMT1 ${ }^{\mathrm{KO}}$ OLs displayed an immature morphology and lower levels of mature OL markers, and proliferate more than control OPCs at 4 DIV (Fig. 3C-E). In contrast, OPCs infected with the control lentivirus showed normal levels of proliferation and morphological changes, which is characteristic of mature OLs (Fig. 3C-E). These data were confirmed by Western blots in which we found decreased DMT1 and myelin protein expression in DMT1 ${ }^{\mathrm{KO}}$ OLs (Fig. $3 F$ ). Overall, these results suggest that DMT1 expression is crucial for cortical OPC maturation in vitro. OLs lacking DMT1 exhibited a simple, less developed morphology and displayed lower levels of iron uptake and myelin protein expression than control cells. Furthermore, in agreement with a maturational interruption, DMT1deficient OPCs showed higher proliferation rates than normal cells after mitogen removal.

\section{DMT1 is necessary for normal OL maturation and}

myelination in vivo

To determine whether DMT1 is required for OPC development in vivo, a conditional knock-out mouse for DMT1 in OPCs was generated by cross-breeding the floxed mutant DMT1 mouse (Gunshin et al., 2005; Carlson et al., 2009) with the NG2CreER transgenic line (Zhu et al., 2011). Floxed DMT1 mice were successfully used to generate a conditional knock-out mouse in which DMT1 was postnatally deleted in hippocampal neurons (Carlson et al., 2009). NG2CreER transgenic mice express a tamoxifen-inducible Cre recombinase under the control of the mouse NG2 (Cspg4) promoter/enhancer, which restricts Cre 
A

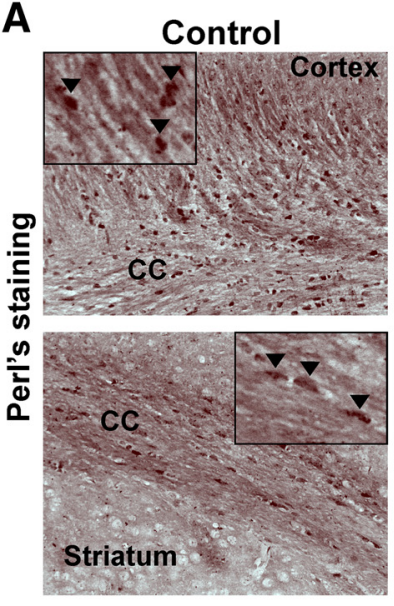

D

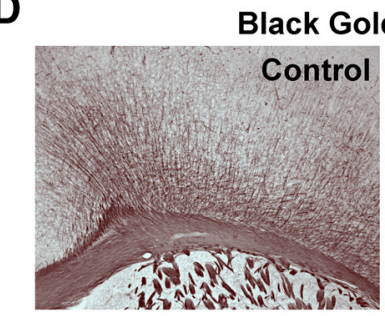

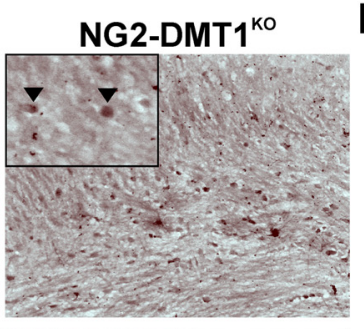

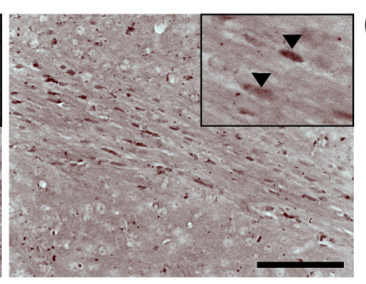

staining

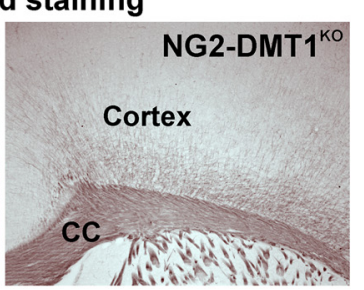

B
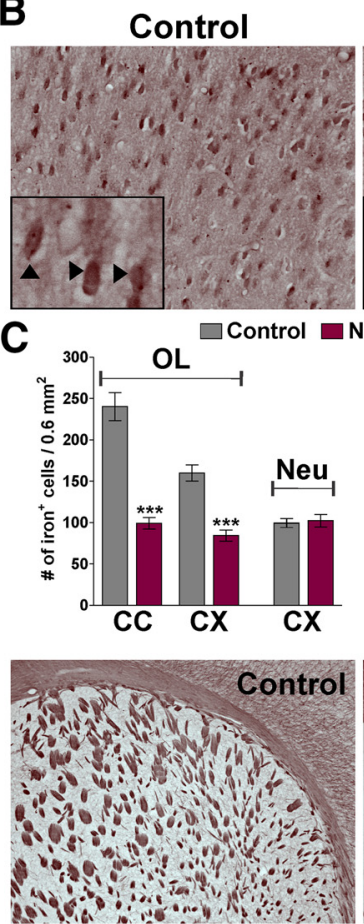
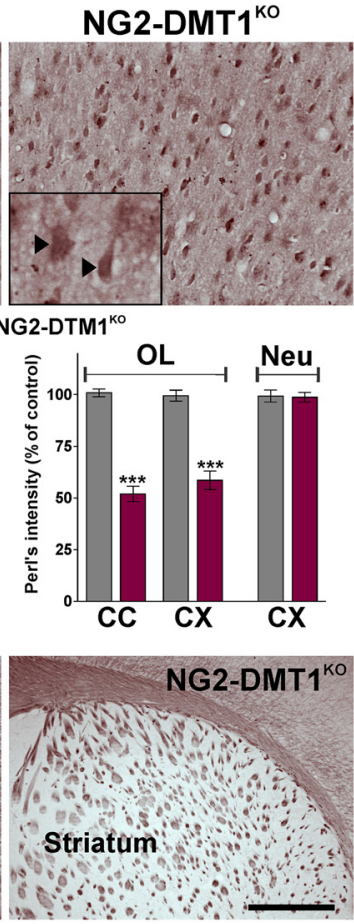

E

$\mathbf{F}$
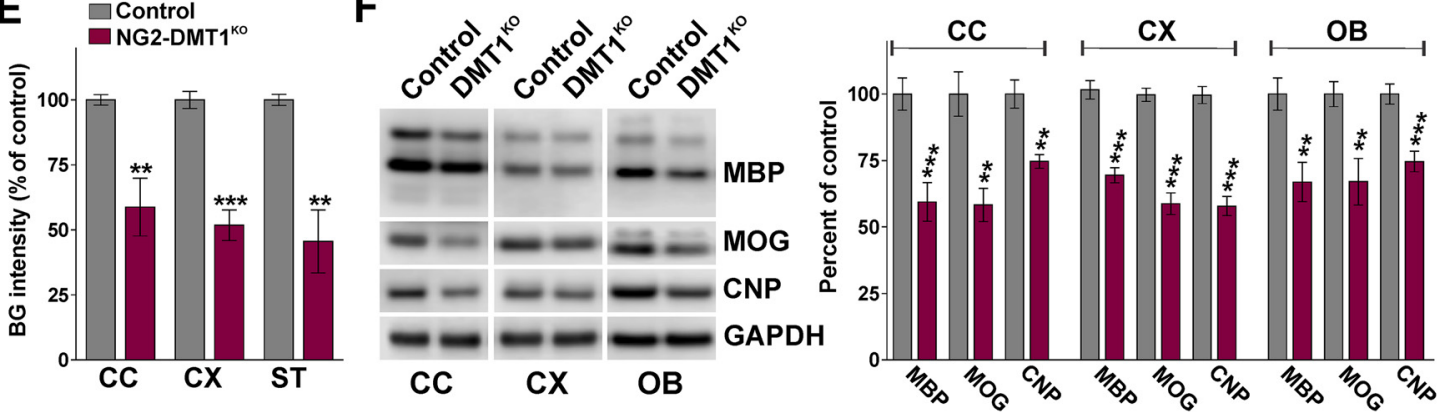

Figure 4. Perl's and Black Gold staining in the NG2-DMT1 ${ }^{\mathrm{K} 0}$ brain. $A, B$, Perl's staining in representative coronal sections of brain tissue collected from control and NG2-DMT1 ${ }^{\mathrm{K} 0}$ mice at P30. Arrowheads in high-magnification insets indicate Perl's positive cells that were selected for the analysis. Scale bars: (in $\boldsymbol{A}) \boldsymbol{A}, 90 \mu \mathrm{m}$; (in $\boldsymbol{A}$ ), $\boldsymbol{B}, 70 \mu \mathrm{m}$. $\boldsymbol{C}$, The total number of Perl's positive $0 \mathrm{Ls}$ and the average intensity staining per cell was quantified in the central area of the corpus callosum (CC) and in the cortex (CX) at P30. Additionally, the total number of Perl's positive neurons (Neu) and the average intensity staining per cell were quantified in the motor cortex. Exact $p$ values from left to right: $<0.0001 ;<0.0001 ; 0.7601 ;<0.0001 ;<0.0001 ; 0.8658$. D, Black Gold II staining in representative coronal sections of brain tissue collected from control and NG2-DMT1 ${ }^{\mathrm{K} 0}$ mice at P30. Scale bar, $180 \mu \mathrm{m}$. E, Black Gold II intensity staining was quantified in the central area of the CC, in the $C X$, and in the striatum (ST) at P30. Exact $p$ values from left to right: $0.0066 ;<0.0001 ; 0.0022$. $F$, Total proteins were collected from the corpus callosum, cortex, and olfactory bulb (0B) at P30 to assess the expression of myelin proteins by Western blot. Representative Western blots are shown. GAPDH was used as the internal standard, and data from six independent experiments are summarized based on the relative spot intensities and plotted as a percentage of controls. Exact $p$ values from left to right: $0.0005 ; 0.0010 ; 0.0064 ;<0.0001 ;<0.0001 ;<0.0001 ; 0.0030 ; 0.0045$; 0.0006 . Comparisons between experimental groups were made by the unpaired $t$ test. Six brains per experimental condition were analyzed, and values are expressed as the mean $\pm S E M .{ }^{* *} p<$ $0.01,{ }^{* * *} p<0.001$ vs respective controls.

expression to OPCs (Zhu et al., 2011; Cheli et al., 2016). To delete DMT1 in NG2-positive OPCs, Cre activity was induced starting at $\mathrm{P} 10$ by intraperitoneal injection of tamoxifen. DMT1 conditional knock-out mice $\left(\mathrm{NG} 2-\mathrm{DMT} 1^{\mathrm{KO}}\right.$; DMT1 ${ }^{\mathrm{f} / \mathrm{f}}$, $\mathrm{NG} 2 \mathrm{CreER} \mathrm{Ere}^{\mathrm{Cr}-}$ ) and control (Cre negative) littermates (DMT1 ${ }^{\mathrm{f} / \mathrm{f}}$, $\mathrm{NG} 2 \mathrm{CreER}{ }^{-/-}$) were injected once a day for 5 consecutive days with tamoxifen, and brain tissue was collected at P30. OL iron incorporation was evaluated using enhanced Perl's histochemistry. Compared with controls, NG2-DMT1 ${ }^{\mathrm{KO}}$ brains display a significant reduction in the total number of iron-positive OLs as well as an important decrease in the average Perl's staining intensity per cell (Fig. $4 A, C$ ). Suggesting an OL-specific iron deficiency, NG2-DMT1 ${ }^{\mathrm{KO}}$ mice showed normal levels of Perl's staining in cortical neurons (Fig. $4 B, C$ ) and at brain iron enriched areas such as the globus pallidus and substantia nigra (data not shown).
The postnatal myelination of the NG2-DMT1 ${ }^{\mathrm{KO}}$ mouse was initially examined using the Black Gold II staining technique to localize myelin within the CNS. NG2-DMT1 ${ }^{\mathrm{KO}}$ mice display a substantial reduction in myelin staining in the corpus callosum, cortex, and striatum (Fig. 4D,E). Additionally, total proteins were collected from the corpus callosum, cortex, and olfactory bulb to evaluate the expression of myelin proteins by Western blot (Fig. 4F). The olfactory bulb was included in this set of experiments because it is one of the most active areas of myelin production in the postnatal mouse brain (Garcia-Gonzalez et al., 2013). In agreement with the Black Gold staining, the expression levels of MBP, MOG, and CNP were significantly decreased in NG2-DMT1 ${ }^{\mathrm{KO}}$ brains (Fig. $4 F$ ). In the same line, immunohistochemical analysis for myelin proteins showed a reduced expression of MBP and MOG in the corpus callosum, cortex, and striatum of NG2-DMT1 ${ }^{\mathrm{KO}}$ mice at P30 (Fig. $5 A, B$ ). Likewise, the 
A
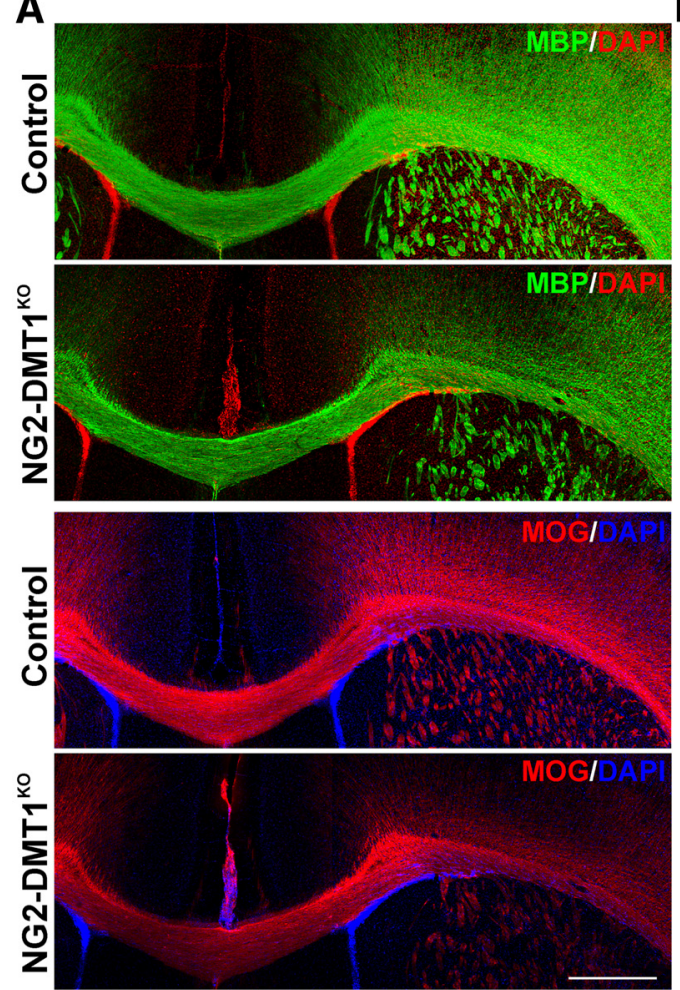

B

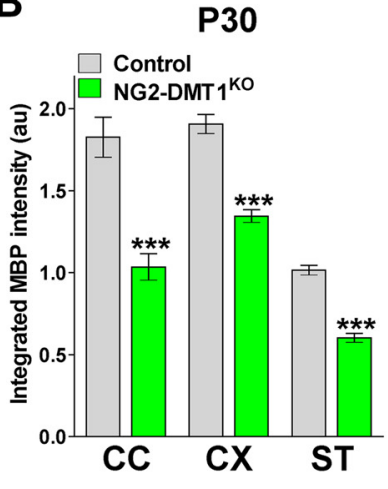

P30

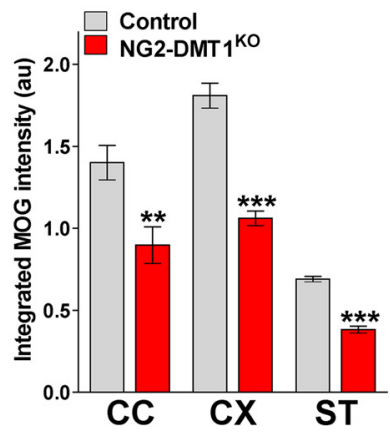

C

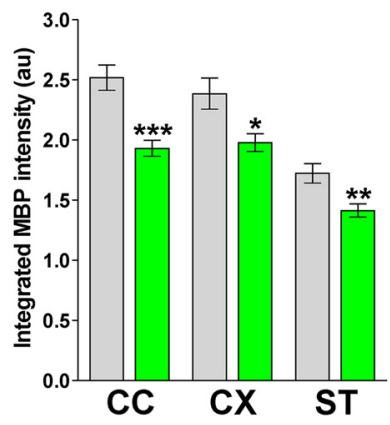

P60

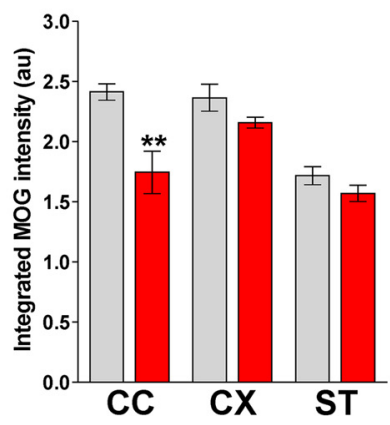

Figure 5. Expression of myelin proteins in the postnatal NG2-DMT1 ${ }^{\mathrm{K} 0}$ mouse. $A, \mathrm{MBP}$ and MOG immunostaining in the brains of control and NG2-DMT1 ${ }^{\mathrm{K} 0}$ mice at $\mathrm{P} 30$. Representative brain coronal sections are shown. Scale bar, $180 \mu \mathrm{m} . B, C$, Myelin was quantified by analyzing the integrated fluorescence intensity of MBP and MOG in the central area of the corpus callosum (CC), the cortex (CX), and in the striatum (ST) at P30 and P60. Exact $p$ values from left to right: MBP-P30: $<0.0001 ;<0.0001 ;<0.0001 ;$ M0G-P30: 0.025; 0.0001; <0.0001; MBP-P60: 0.0007; 0.0283; 0.0087; MOG-P60: $0.0012 ; 0.1379 ; 0.1655$. Comparisons between experimental groups were made by the unpaired $t$ test. Six brains per experimental condition were analyzed, and values are expressed as the mean \pm SEM. ${ }^{*} p<0.05,{ }^{* *} p<0.01,{ }^{* * *} p<0.001$ vs respective controls.

expression of MBP and MOG was found to be below control levels in several brain areas of NG2-DMT1 ${ }^{\mathrm{KO}}$ animals at P60 (Fig. $5 C$ ), suggesting that the hypomyelination found in young NG2DMT1 ${ }^{\mathrm{KO}}$ mice is persistent throughout adulthood.

The NG2-DMT1 ${ }^{\mathrm{KO}}$ brain was also evaluated by electron microscopy. The degree of myelination was analyzed at P30 in the body of the corpus callosum by calculating the fraction of myelinated axons and the g-ratio, as described previously (Cheli et al., 2016; Fig. 6). An important reduction in the percentage of myelinated axons without changes in the mean g-ratio was found in NG2-DMT1 ${ }^{\mathrm{KO}}$ animals (Fig. $6 A-D, F$ ). Importantly, no changes in the frequency distribution of axonal diameter were found in the corpus callosum of NG2-DMT1 ${ }^{\mathrm{KO}}$ mice (Fig. $6 E$ ). To further examine the effect of DMT1 deletion in OPC development, OL markers such as Olig2 and CC1 were used to measure OL numbers and maturation in the corpus callosum, cortex, and striatum. No changes in the total number of Olig2-positive cells were found, but the density of mature CC1-positive OLs was significantly lower in the NG2-DMT1 ${ }^{\mathrm{KO}}$ brain at both P30 and P60 (Fig. 7A,B). OPC proliferation was evaluated using the mitotic marker Ki67 in combination with the OL marker Olig2, and the proportion of immature OLs was assessed mixing Olig2 with the transcription factor Olig1 (Fig. $7 C, D$ ). Suggesting a rise in the rate of OPC proliferation, NG2$\mathrm{DMT} 1{ }^{\mathrm{KO}}$ mice displayed a significant increase in the percentage of Olig2/Ki67 and Olig2/Olig1 double-positive cells in the corpus callosum and cortex at P30 (Fig. 7C,D).

Myelination and OPC maturation was also analyzed in a DMT1 conditional KO mouse created by breeding the floxed DMT1 mouse with the Sox $10 \mathrm{CreER}{ }^{\mathrm{T} 2}$ line. The Sox $10 \mathrm{CreER}^{\mathrm{T} 2}$ transgenic mouse express a tamoxifen-inducible Cre recombinase under the control of the mouse Sox10 promoter, which limits Cre expression to OLs (Laranjeira et al., 2011; Tripathi et al., 2011). Starting at P2, Sox10-DMT1 ${ }^{\mathrm{KO}}\left(\mathrm{DMT} 1^{\mathrm{f} / \mathrm{f}}\right.$, Sox $\left.10 \mathrm{Cr} e^{\mathrm{Cre} /-}\right)$ and control (Cre negative) littermates (DMT1 ${ }^{\mathrm{f} / \mathrm{f}}$, Sox10Cre ${ }^{-/-}$) were injected once a day for 5 consecutive days with tamoxifen, and brain tissue was collected at P15 and P30. Compared with littermate controls, Sox10-DMT1 ${ }^{\mathrm{KO}}$ mice show a substantial reduction of MBP and PLP immunostaining in the corpus callosum and cortex at both $\mathrm{P} 15$ and $\mathrm{P} 30$ (Fig. 8 A, B). This myelin deficit was accompanied by a decrease in the total number of Olig2positive cells, a decline in the density of myelinating OLs (CC1-positive cells), and a rise in proliferating OPCs in the cortex (Fig. 8C,D). Importantly, no changes in the percentage of apoptotic OLs (Olig2/caspase-3-positive cells) were found (Fig. $8 D$ ). To explore the role of DMT1 in myelinating OLs, immunohistochemical experiments for myelin proteins were performed in adult mice. Since the Sox 10 promoter is highly active in myelinating OLs, Sox $10-\mathrm{DMT} 1{ }^{\mathrm{KO}}$ and control animals were injected with tamoxifen at P60 and brains were collected for analysis at P90. Suggesting that DMT1 is relevant for the function of mature OLs, the expression of MBP and PLP was severely reduced in P90 Sox10-DMT1 ${ }^{\mathrm{KO}}$ mice (Fig. $8 A, B)$. No changes in the percentage of Olig2/Ki67 or Olig2/ caspase-3 double-positive cells were found (Fig. $8 D$ ), but the brains of Sox10-DMT1 ${ }^{\mathrm{KO}}$ mice at $\mathrm{P} 90$ showed a significant reduction in the total number of Olig2- and CC1-expressing cells (Fig. 8D). These results imply that the decline in myelin protein expression at $\mathrm{P} 90$ is due to reduced numbers of mature OLs. 
A

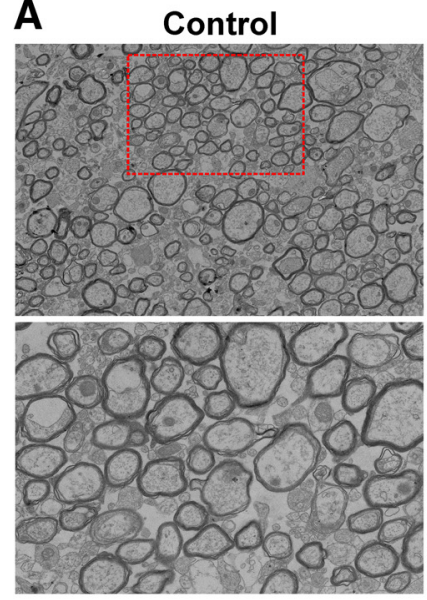

C

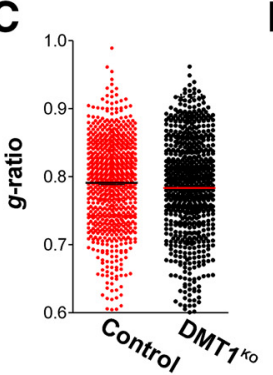

D

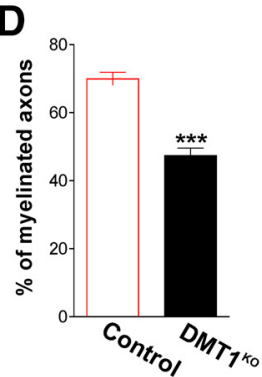

NG2-DMT1 ${ }^{\text {Ko }}$

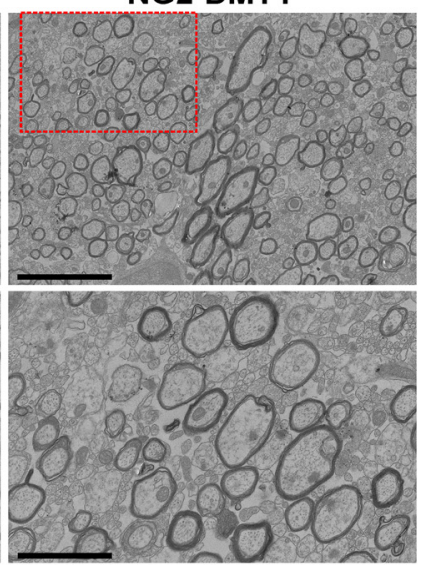

E

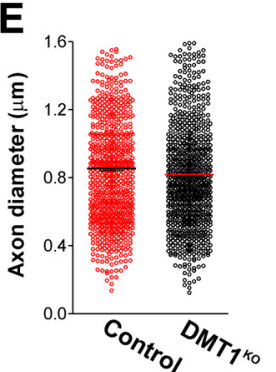

B

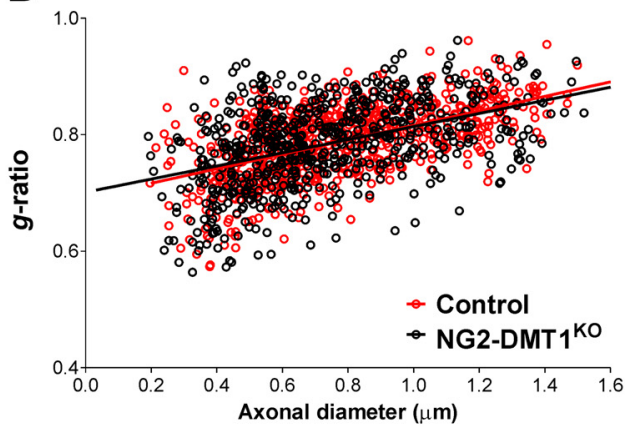

$\mathbf{F}$

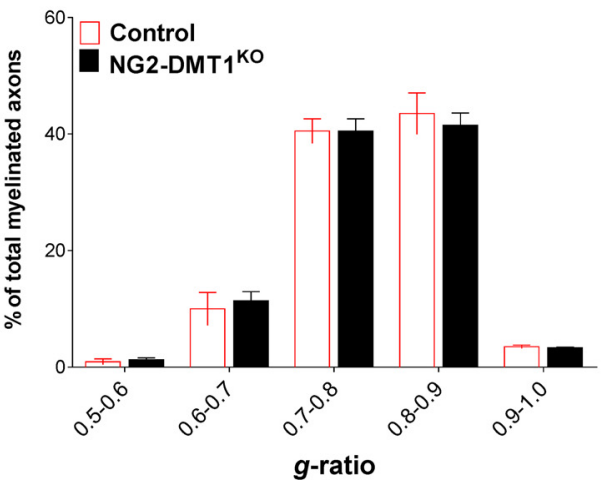

Figure 6. Electron microscopy of the NG2-DMT $1{ }^{\mathrm{K} 0}$ corpus callosum. $\boldsymbol{A}$, Electron micrographs of axons in the corpus callosum of control and NG2-DMT1 ${ }^{\mathrm{K} 0}$ mice at P30. Scale bars: top, $8 \mu \mathrm{m}$; bottom, $2 \mu \mathrm{m}$. $\boldsymbol{B}$, Scatter plot of g-ratio values of control and NG2-DMT1 ${ }^{\mathrm{K} 0}$ mice at P30. The lines represent the regression equation with $95 \%$ confidence intervals. Control: $r^{2}, 0.3351 ;$ slope, 0.1242 ; 1/slope, 8.050; F, 348.3. NG2-DMT1 ${ }^{\mathrm{KO}}: r^{2}, 0.2106$; slope, $0.1126 ; 1 /$ slope, 8.881; F, 168.3. C, Mean g-ratio values of control and NG2-DMT1 ${ }^{\mathrm{K} 0}$ mice at P30. Exact $p$ value: 0.0591 . D, Percentage of myelinated axons of control and NG2-DMT1 ${ }^{\mathrm{KO}}$ mice at P30. Exact $p$ value, $<0.0001$. E, Mean axonal diameter in control and NG2-DMT1 ${ }^{\mathrm{K} 0}$ mice fibers at P30. Exact $p$ value, 0.0532 . $F$, Distribution of $g$-ratio values at $P 30$. Exact $p$ values from left to right: $0.4768 ; 0.6021 ; 1.0000 ; 0.5636 ; 0.4655$. Comparisons between experimental groups were made by the unpaired $t$ test. Values are expressed as the mean \pm SEM. Four animals per experimental group and 150 fibers per animal were analyzed. ${ }^{* * *} p<0.001$ vs control.

\section{DMT1 is key for the remyelination of the adult brain}

The role of DMT1 on myelin loss and recovery was examined in the NG2-DMT1 ${ }^{\mathrm{KO}}$ line using the cuprizone model of demyelination (Ludwin, 1978; Matsushima and Morell, 2001; Armstrong et al., 2006; Islam et al., 2009). P60 NG2-DMT1 ${ }^{\mathrm{KO}}$ mice $\left(\mathrm{DMT} 1^{\mathrm{f} / \mathrm{f}}\right.$, $\mathrm{NG} 2 \mathrm{CreER}{ }^{\mathrm{Cre} /-}$ ) and control (Cre negative) littermates $\left(\mathrm{DMT}_{1}^{\mathrm{f} / \mathrm{f}}, \mathrm{NG} 2 \mathrm{CreER}{ }^{-/-}\right.$) were fed $0.2 \%$ cuprizone for 7 weeks to induce myelin damage, followed by a return to the standard diet for 2 and 4 weeks to allow remyelination. To delete DMT1 in OPCs, NG2-DMT1 ${ }^{\mathrm{KO}}$ mice and control littermates were injected with tamoxifen every other day during the last week of the cuprizone treatment and through the first week of recovery. In addition, P60 control (DMT1 ${ }^{\mathrm{f} / \mathrm{f}}, \mathrm{NG} 2 \mathrm{CreER}{ }^{-/-}$) mice were maintained on a diet of normal pellet chow (untreated) or were not injected and were just treated with CPZ during 7 weeks. Initially, the expression of myelin proteins was evaluated in the corpus callosum and cortex by immunohistochemistry and Western blot (Fig. 9). No differences between genotypes were found at the end of the cuprizone treatment; compared with noninjected cuprizone-treated animals, tamoxifen-treated control and NG2-DMT1 ${ }^{\mathrm{KO}}$ mice displayed an equal decline in MBP and PLP immunostaining (Fig. 9A,B). However, relative to controls, an important reduction in the levels of MBP and PLP was found in the corpus callosum and cortex of NG2-DMT1 ${ }^{\mathrm{KO}}$ mice after 2 and 4 weeks of recovery (Fig. 9A,B). These results were confirmed by Western blot experiments in which MBP and CNP quantities were significantly reduced in NG2-DMT1 ${ }^{\mathrm{KO}}$ samples after 2 weeks of recovery (Fig. 9C). In the same line, the density of mature CC1positive OLs as well as the number of Olig2-positive cells were found to be below control levels in the NG2-DMT1 ${ }^{\mathrm{KO}}$ brain 2 weeks after the termination of the cuprizone treatment (Fig. 10 A,B). Consistently, the fraction of mature OLs (Olig2/CC1-positive cells) was reduced and the amount of proliferating immature OPCs (Olig2/ Ki67-positive cells) was increased in NG2-DMT1 ${ }^{\mathrm{KO}}$ brains after 2 weeks of recovery (Fig. 10C).

Finally, the degree of remyelination was analyzed in the body of the corpus callosum by electron microscopy (Fig. 11). Seven weeks of cuprizone treatment induced a significant decrease in the percentage of myelinated axons (Figure $11 A, F$ ). Opposite to controls, which show a significant recovery, NG2-DMT1 ${ }^{\mathrm{KO}}$ mice display almost no improvement in the proportion of myelinated axons after 2 weeks of normal diet (Figure 11C,F). Additionally, to assess axonal remyelination, the g-ratio was determined for NG2-DMT1 ${ }^{\mathrm{KO}}$ and control mice (Fig. $11 B, D, E$ ). Suggesting a reduction in myelin thickness, the mean g-ratio of myelinated axons was increased in the NG2-DMT1 ${ }^{\text {KO }}$ corpus callosum after 2 weeks of recovery (Fig. $11 D, E)$. Plotting g-ratios against axonal diameters demonstrated that the myelin thickness was lower in axons of all size (Fig. 11D). Importantly, during the recovery phase of the cuprizone model, no variations in the mean diameter of myelinated axons were found (Fig. 11G). In summary, our data suggest that DMT1 is essential for OPC maturation and for the appropriate remyelination of the mouse brain.

\section{Discussion}

DMT1 is crucial for iron uptake and normal OPC maturation Our results show that DMT1 is an important player in OL iron homeostasis. We found that OL iron uptake is diminished when 
A

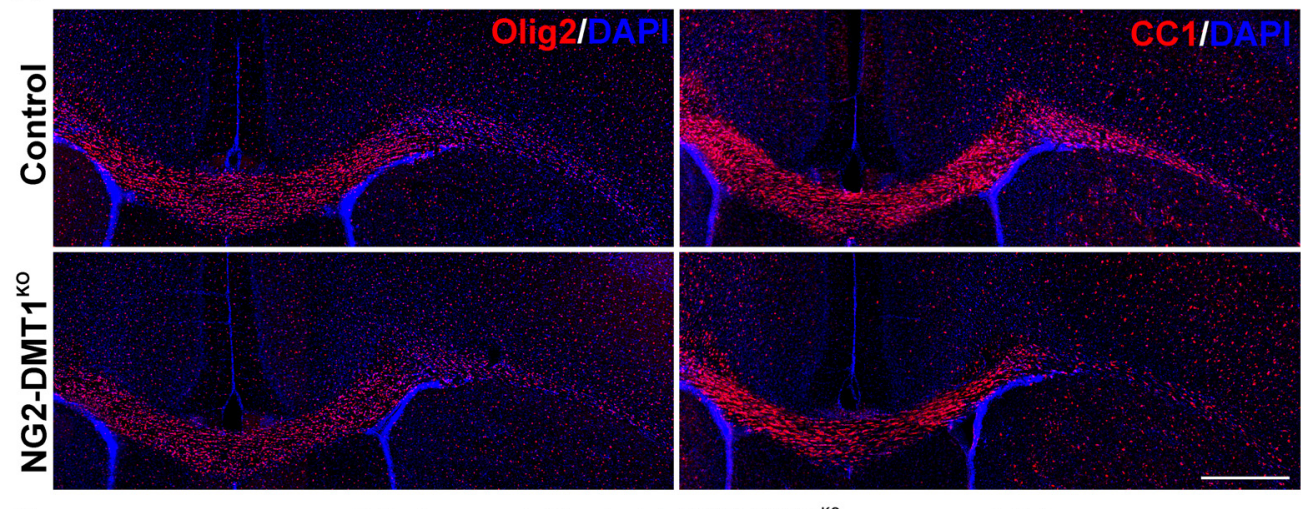

B
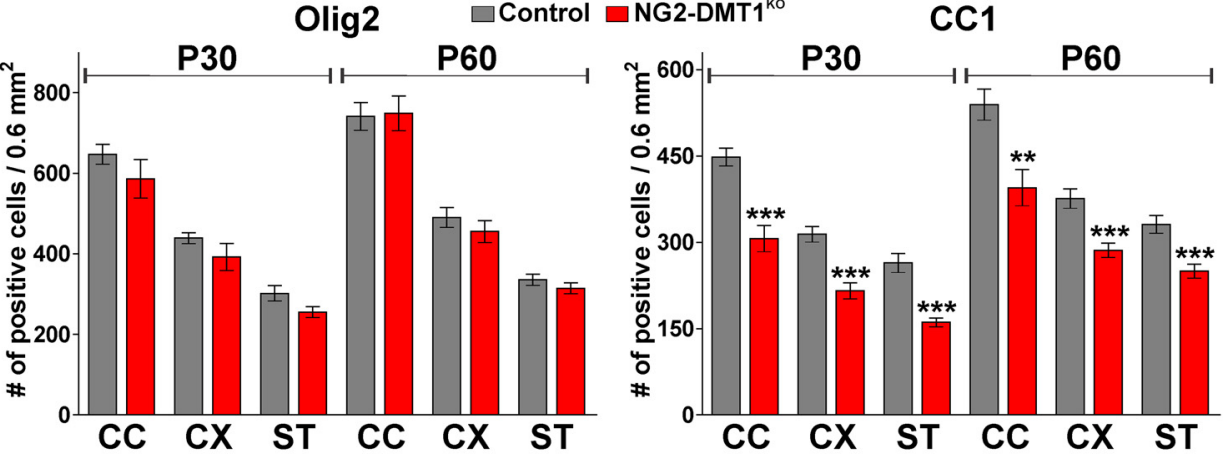

C
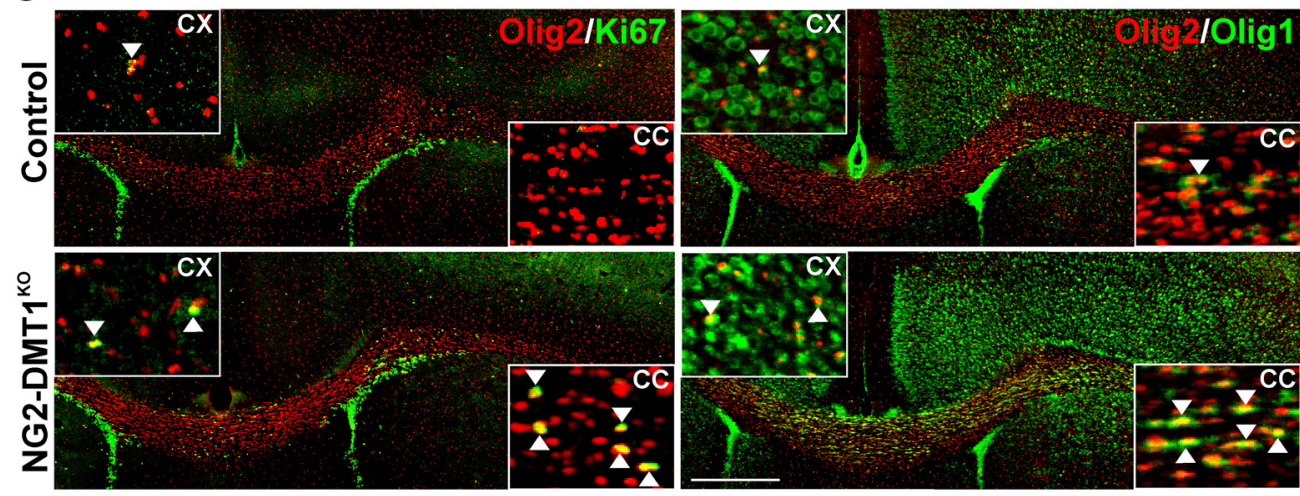

D

Olig2 / Ki67
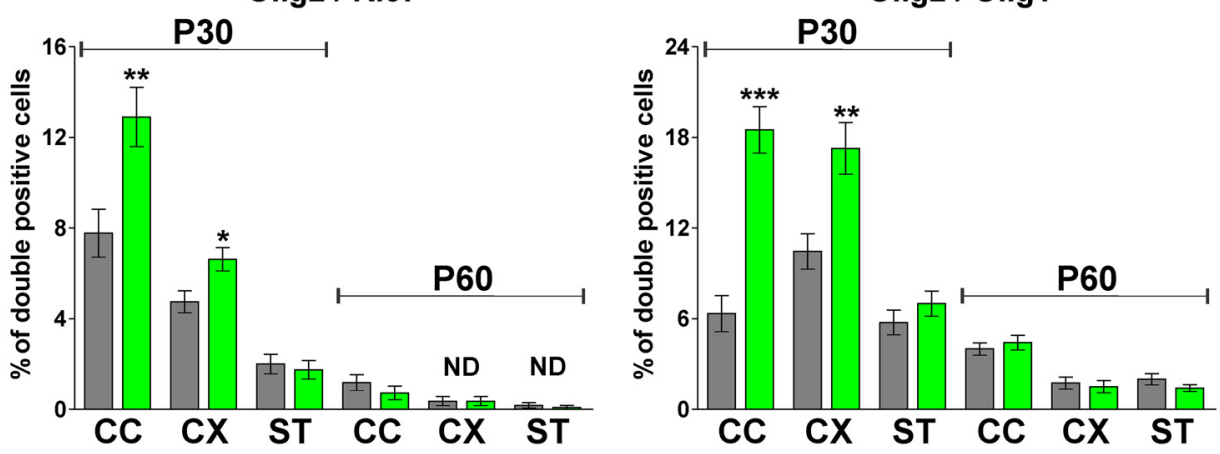

Figure 7. A decreased number of mature $0 \mathrm{Ls}$ in the NG2-DMT1 ${ }^{\mathrm{K} 0}$ mouse. A, C, Representative coronal sections of control and NG2-DMT ${ }^{\mathrm{K} 0}$ brains at $\mathrm{P} 30$ immunostained for 0 lig2, $\mathrm{CC} 1$, and the combination of 0lig2/Ki67 and Olig2/0lig1. Scale bar, $180 \mu \mathrm{m}$. Arrowheads in high-magnification insets indicate examples of double-positive cells that were selected for the analysis. B, D, The number of 0lig2 and (C1-positive cells and the percentage of Olig2/Ki67 and 0lig2/Olig1 double-positive cells was quantified in the central area of the corpus callosum (CC), in the cortex (CX), and in the striatum (ST) at P30 and P60. Exact $p$ values from left to right: Olig2: $0.2738 ; 0.2125 ; 0.0604 ; 0.8876 ; 0.3629 ; 0.2998 ; C(1:<0.0001 ;<0.0001 ;<0.0001 ; 0.0023 ; 0.0003 ; 0.0005 ; 0$ lig2/Ki67: $0.0078 ; 0.0123 ; 0.6769 ; 0.3403 ; 1,0000 ; 0.5568 ; 0$ lig2/0lig1: $<0.0001 ; 0.0036 ; 0.2937 ; 0.5173 ; 0.6591 ; 0.1931$. Comparisons between experimental groups were made by the unpaired $t$ test. Six brains per experimental condition were analyzed, and values are expressed as the mean \pm SEM. ${ }^{*} p<0.05,{ }^{* *} p<0.01,{ }^{* * *} p<0.001$ vs respective controls. 
A

P15

P90

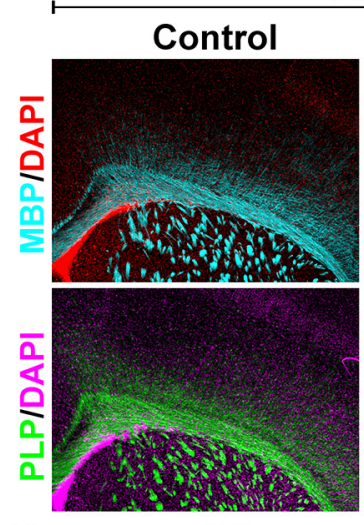

B

CC

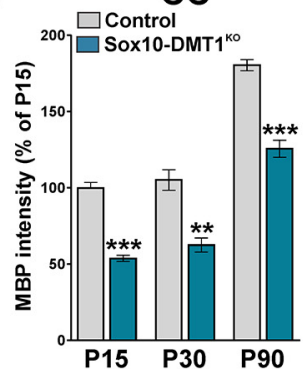

Sox10-DMT1 ${ }^{\mathrm{ko}}$

Control
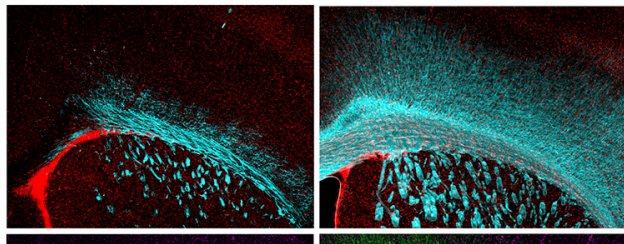

Sox10-DMT1 ${ }^{\mathrm{KO}}$
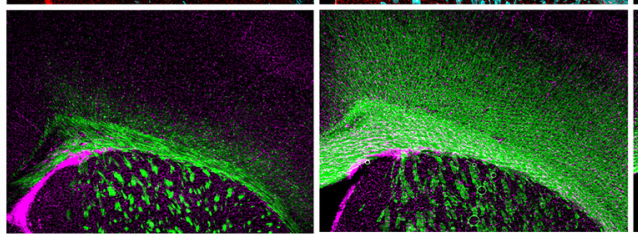

CX

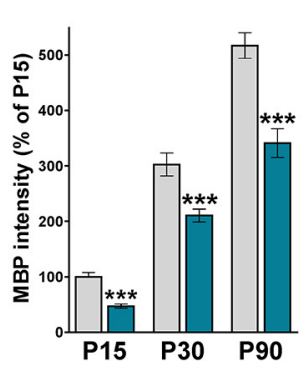

CC
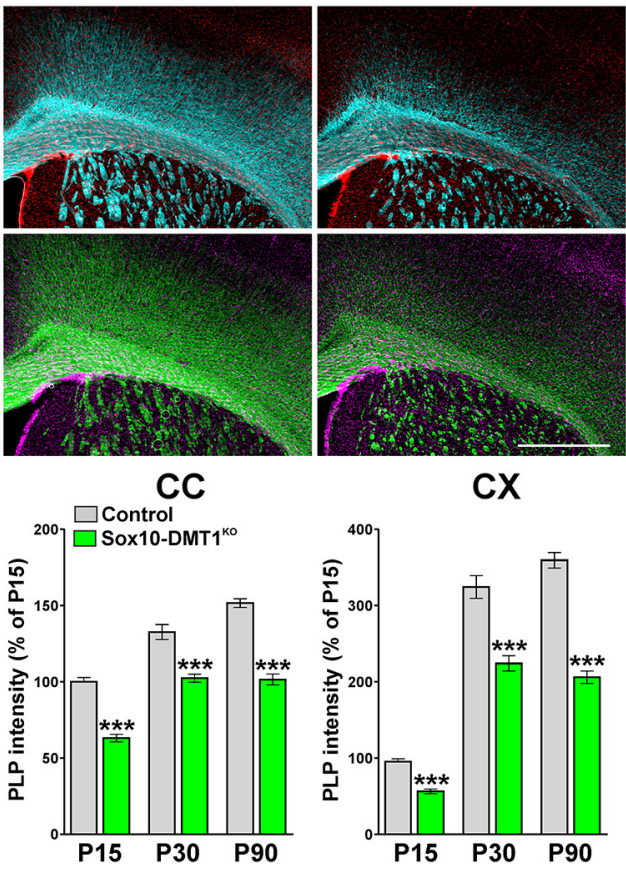

C

P15
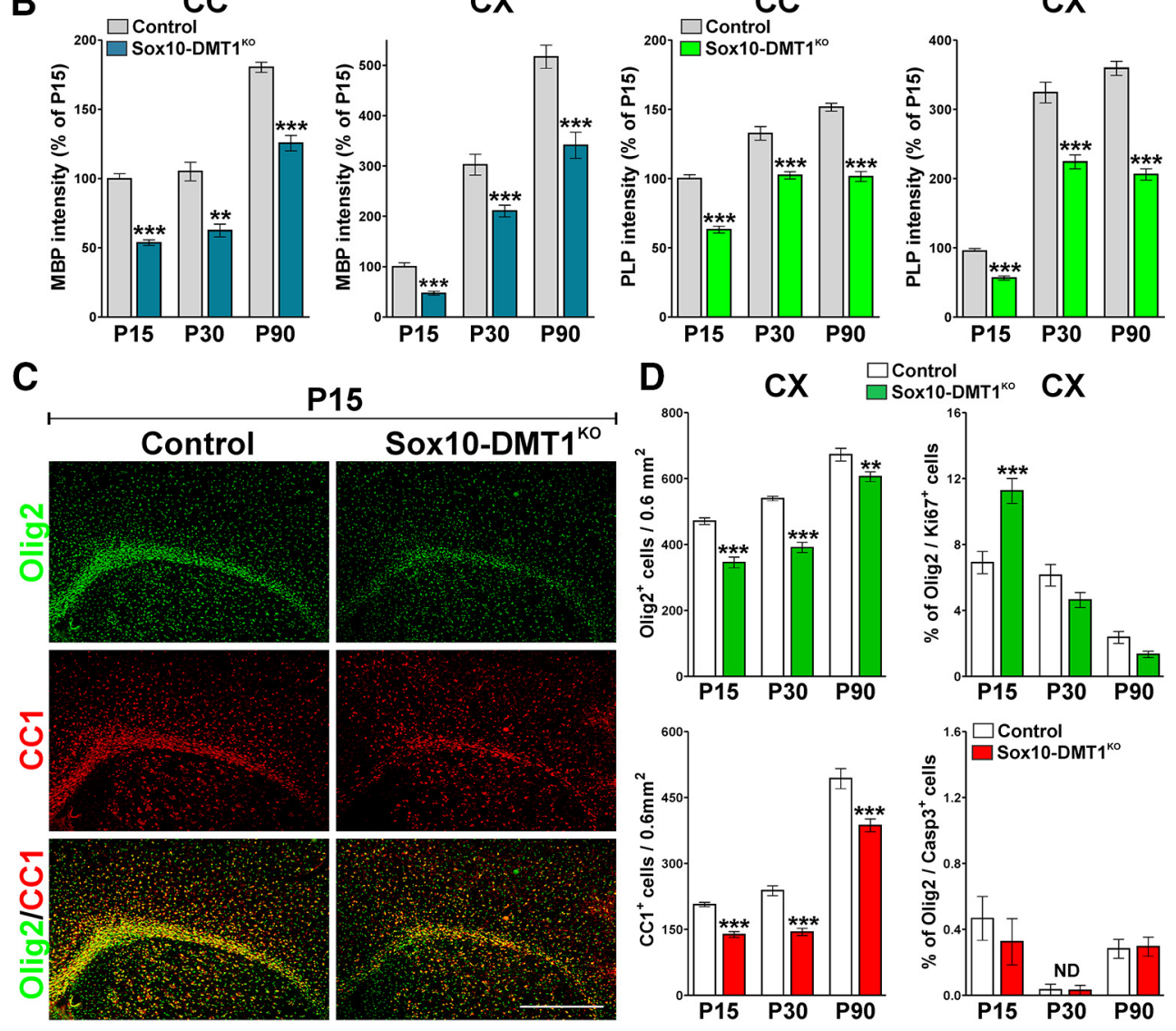

Figure 8. Myelination in the Sox10-DMT1 ${ }^{\mathrm{K} 0}$ brain. $A, \mathrm{MBP}$ and PLP immunostaining in the brains of control and Sox $10-\mathrm{DMT} 1{ }^{\mathrm{K} 0}$ mice at P15 and P90. Representative brain coronal sections are shown. Scale bar, $180 \mu \mathrm{m}$. B, The integrated fluorescence intensity of MBP and PLP was quantified in the central area of the corpus callosum (CC) and in the cortex (CX) at P15, P30, and P90, and plotted as a percentage of P15 controls. Exact $p$ values from left to right: MBP-CC: $<0.0001 ;<0.0001 ;<0.0001 ;$ MBP-CX: $<0.0001 ; 0.0002 ; 0.0001 ;$ PLP-CC: $<0.0001 ;<0.0001 ;<0.0001$; PLP-CX: $<0.0001 ;<0.0001 ;<0.0001$. C, Representative coronal sections of control and Sox 10-DMT1 ${ }^{\mathrm{K} 0}$ brains immunostained for 0 lig2 and CC1 at P15. Scale bar, $180 \mu \mathrm{m} . \boldsymbol{D}$, The number of 0 lig 2 and CC1-positive cells and the percentage of Olig2/Ki67 and 0lig2/caspase-3 double-positive cells was quantified in the cortex (CX) at P15, P30, and P90. Exact $p$ values from left to right: Olig2: $<0.0001$; $<0.0001$; Olig2/Ki67: 0.0007; 0.0710; $\subset(C 1:<0.0001 ;<0.0001$; 0lig2/caspase3: 0.4736 . Comparisons between experimental groups were made by one-way ANOVA followed by Bonferroni's multiple-comparison test. Six brains per experimental condition were analyzed, and values are expressed as the mean \pm SEM. ${ }^{* *} p<0.01$, ${ }^{* * *} p<0.001$ vs respective controls.

DMT1 is knocked down in primary cultures of cortical OPCs and OPCs lacking DMT1 failed to morphologically mature and displayed low levels of mature markers and myelin proteins expression in vitro. Additionally, DMT1-deficient OPCs showed higher proliferation rates than control cells, suggesting a maturational delay. These in vitro results, in which DMT1 was knocked out in postnatal OPCs, were confirmed in vivo. Immunohistochemical and Western blot studies performed during the postnatal development of the moue brain (P15/P30) revealed lower expression levels of myelin proteins in several areas of NG2-DMT1 ${ }^{\mathrm{KO}}$ and Sox10-DMT1 ${ }^{\mathrm{KO}}$ brains, and the corpus callosum of NG2DMT1 ${ }^{\mathrm{KO}}$ animals presented an important decrease in the percentage of myelinated axons. Additionally, NG2-DMT1 ${ }^{\mathrm{KO}}$ as well as Sox10-DMT1 ${ }^{\mathrm{KO}}$ mice exhibited an important reduction in the number of mature myelinating OLs with a concomitant rise in the density of immature proliferating OPCs, this imbalance was probably the main reason for the myelination deficit observed in young DMT $1{ }^{\mathrm{KO}}$ animals. Furthermore, the expres- 
A

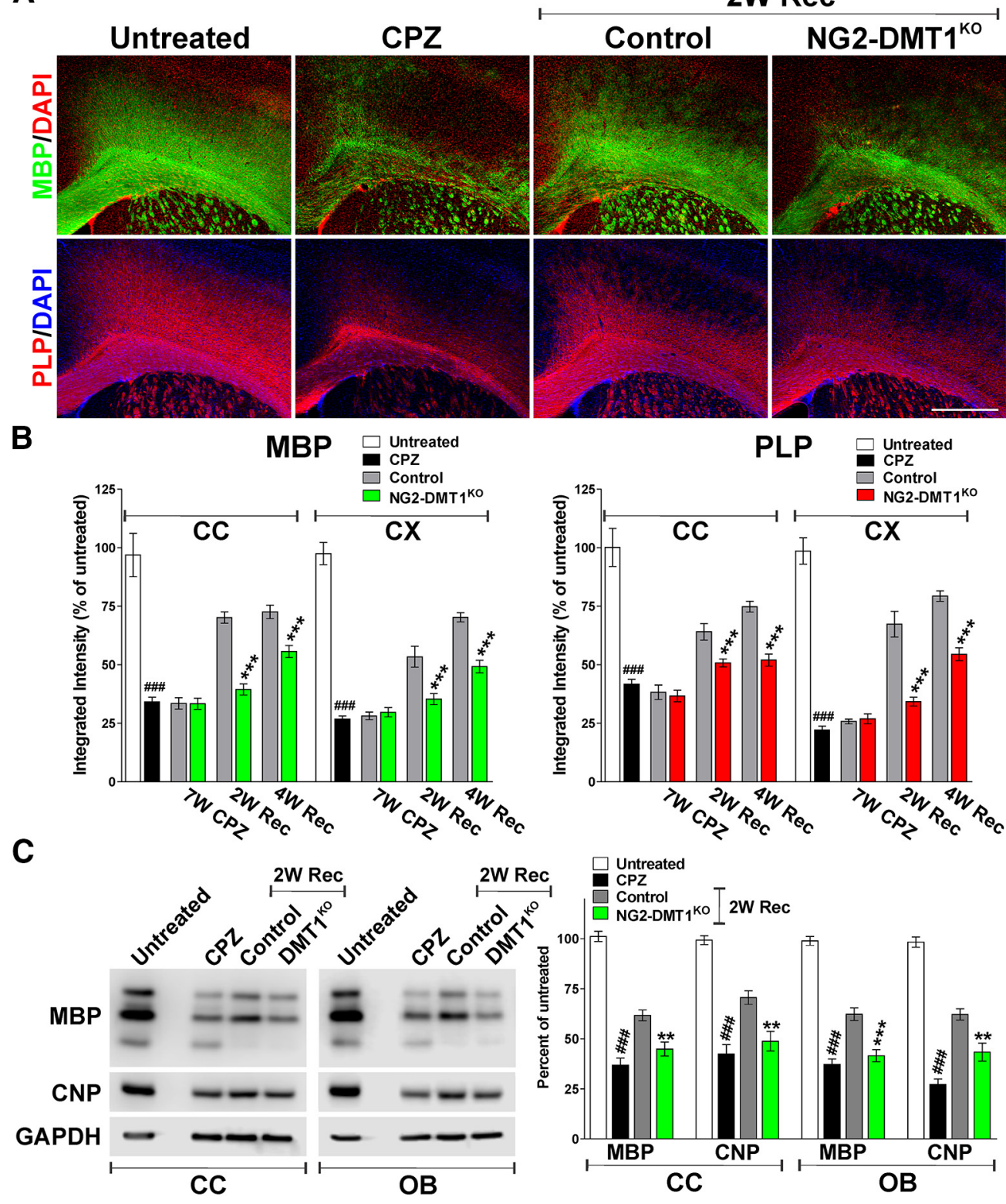

Figure 9. Remyelination in the NG2-DMT1 ${ }^{\mathrm{KO}}$ brain. $A$, Representative coronal sections of brain tissue immunostained for MBP and PLP collected from untreated animals (untreated), mice treated with cuprizone for 7 weeks (CPZ), and control and NG2-DMT1 ${ }^{\mathrm{K} 0}$ mice after 7 weeks of (PZ treatment (7W CPZ) and at 2 weeks of recovery (2W Rec). Scale bar, $180 \mu \mathrm{m}$. B, Myelin was quantified by analyzing the fluorescence intensity of MBP and PLP in the central area of the corpus callosum (CC) and in the cortex (CX). Exact $p$ values from left to right: MBP-CC: $<0.0001 ; 0.9709$; $<0.0001$; $<0.0001$; MBP-CX: $<0.0001 ; 0.5418 ; 0.0001 ;<0.0001$; PLP-CC: $<0.0001 ; 0.6892 ; 0.0002 ;<0.0001 ;$ PLP-CX: $<0.0001 ; 0.6277 ;<0.0001 ;<0.0001$. C, Total proteins were collected from the corpus callosum and olfactory bulb (OB) to assess the expression of MBP and CNP by Western blot. Representative Western blots are shown. GAPDH was used as the internal standard, and data from four independent experiments are summarized based on the relative spot intensities and plotted as percentages of untreated animals. Exact $p$ values from left to right: MBP-CC: $<0.0001 ; 0.0014$; CNP-CC: $<0.0001 ; 0.0017 ; \mathrm{MBP}-0 \mathrm{~B}:<0.0001 ; 0.0002 ; \mathrm{PLP}-0 \mathrm{~B}:<0.0001 ; 0.0025$. Comparisons between experimental groups were made by one-way ANOVA followed by Bonferroni's multiplecomparison test. Six brains per experimental condition were analyzed, and values are expressed as the mean \pm SEM. \#\#\#p $<0.001$ vs untreated; ${ }^{* *} p<0.01$, ${ }^{* * *} p<0.001$ vs control.

sion of MBP and PLP and the density of myelinating OLs were decreased in P60 NG2-DMT1 ${ }^{\mathrm{KO}}$ brains as well as in P90 Sox10$\mathrm{DMT}^{\mathrm{KO}}$ mice in which DMT1 deletion was induced at P60. These results suggest that the reduction in myelin protein expression in adult DMT ${ }^{\mathrm{KO}}$ mice is due to reduced numbers of mature OLs and that myelinating cells need DMT1 for iron uptake. However, P60 NG2-DMT1 ${ }^{\mathrm{KO}}$ animals display a significant recovery in myelin protein synthesis compared with younger P30 DMT1 $1{ }^{\mathrm{KO}}$ mice. Because the recombination efficiency in these animals is $\sim 80 \%$, it is possible that this compensation was sustained by OPC-expressing normal levels of DMT1 or by an augmented myelin production per OL.
Under normal conditions, mammalian cells such as OLs acquire most of their iron via the Tf cycle (Moos et al., 2007). Iron is normally transported in the plasma in the ferric state by $\mathrm{Tf}$ (Ponka, 1997). Transferrin subsequently binds the Tfr on the cell surface, which then undergoes endocytosis, generating endosomal vesicles within the cell. Since DMT1 is essential for endosomal iron exit (for review, see Garrick et al., 2003), it is possible that DMT1 contributes to the OL Tf cycle by accelerating endosomal iron exit. However, most cells are also capable of non-Tfbound iron uptake through DMT1 (Garrick et al., 2003); thus, this could be a second way by which iron is incorporated into OLs. Determining which one of these two mechanisms is the 
A

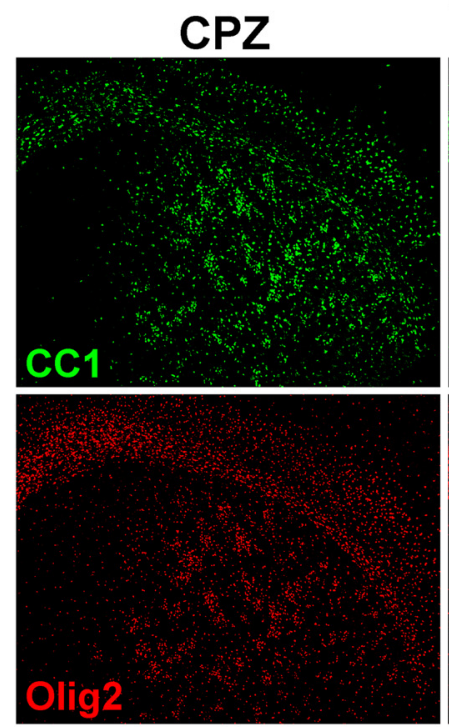

B
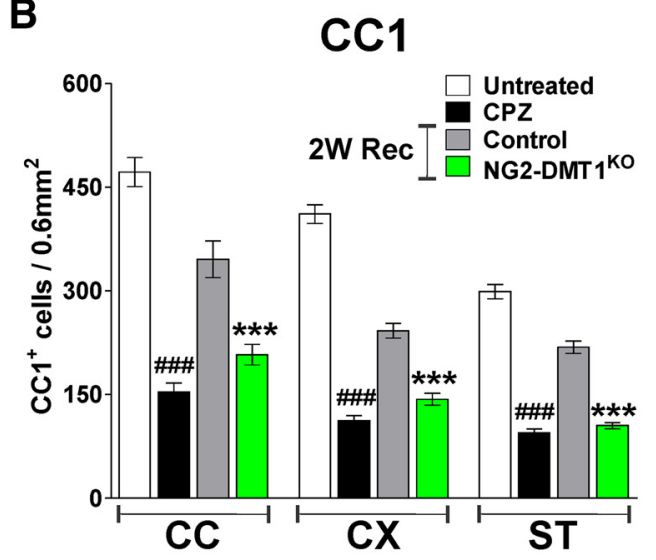

C

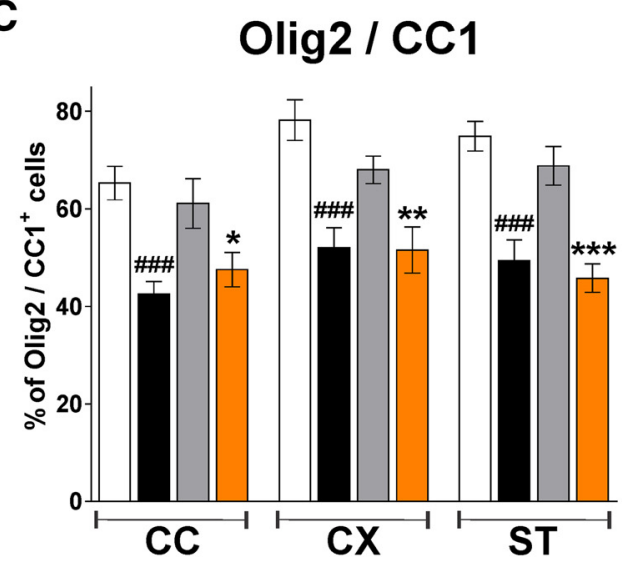

2W Rec

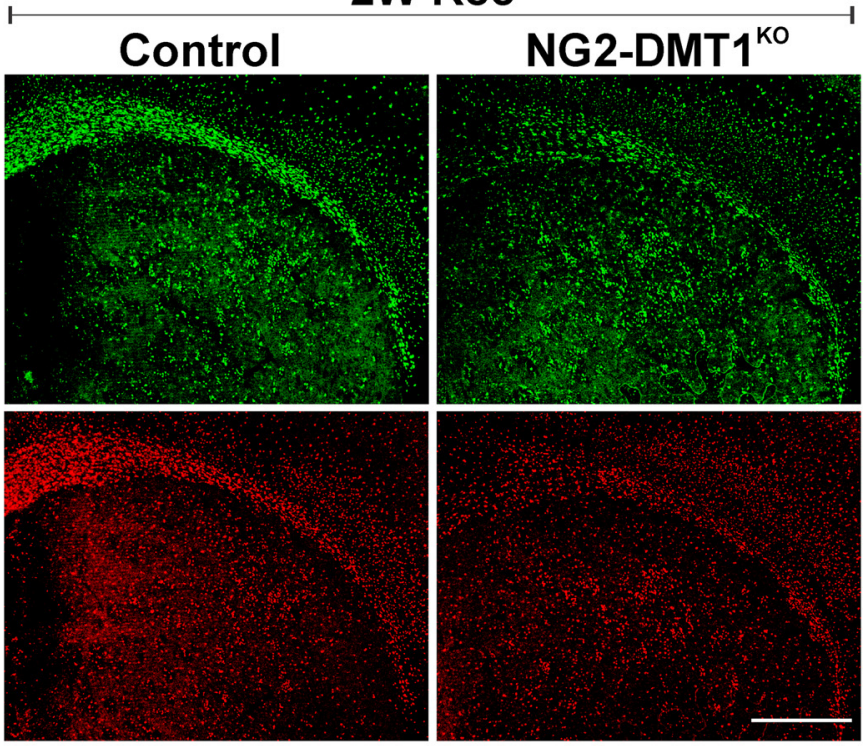

Olig2

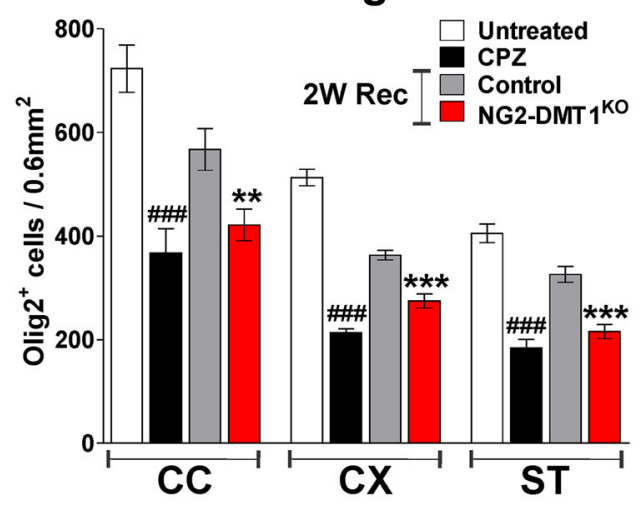

Olig2 / Ki67

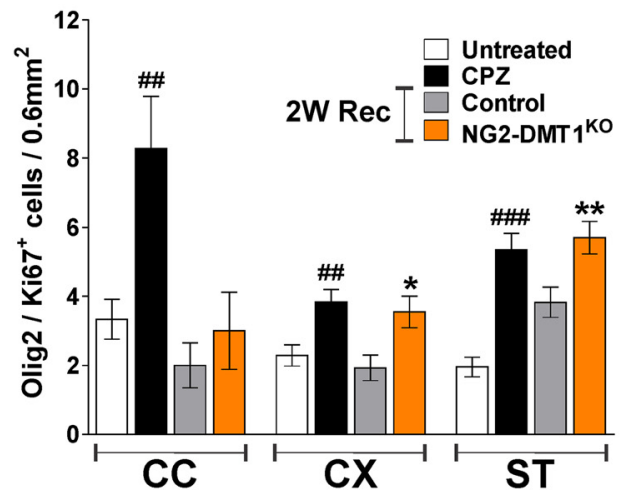

Figure 10. Decreased density of mature $0 \mathrm{Ls}$ during the remyelination of the $\mathrm{NG2}-\mathrm{DMT} 1{ }^{\mathrm{K} 0}$ brain. $A$, Representative coronal sections of brain tissue immunostained for $\mathrm{CC} 1$ and 0 lig 2 collected from cuprizone-treated animals (CPZ) and control and NG2-DMT1 ${ }^{\mathrm{K} 0}$ mice at 2 weeks of recovery (2W Rec). Scale bar, $180 \mu \mathrm{m}$. B, C, The number of CC1-, 0lig2-, and 0lig2/Ki67-positive cells, and the percentage of Olig2/CC1 double-positive cells was quantified in the central area of the corpus callosum (CC), in the cortex (CX), and in the striatum (ST). Exact p values from left to right: $C(1):<0.0001$; $<0.0001 ;<0.0001 ;<0.0001 ;<0.0001 ;<0.0001 ; 0$ lig2: $<0.0001 ; 0.0040 ;<0.0001 ;<0.0001 ;<0.0001 ;<0.0001 ; 0$ lig2/CC1: $<0.0001 ; 0.0332 ;<0.0001 ; 0.0049 ;<0.0001 ;<0.0001 ;$ Olig2/Ki67: $0.0049 ; 0.4664 ; 0.0022 ; 0.0210 ;<0.0001 ; 0.0056$. Comparisons between experimental groups were made by one-way ANOVA followed by Bonferroni's multiple-comparison test. Six brains per experimental condition were analyzed, and values are expressed as the mean \pm SEM. \#\#\#p $<0.001$ vs untreated; ${ }^{*} p<0.05,{ }^{* *} p<0.01,{ }^{* * *} p<0.001$ vs control.

most active in OLs and how these two possible alternatives of iron assimilation changes during the maturation of OPCs needs to be elucidated in future experiments. DMT1B was the sole isoform found in cortical OPCs. This DMT1 isoform was upregulated during OPC maturation and was found to hold an IRE only in mature OLs. This indicates that in developed OLs, DMT1B synthesis may be controlled post-translationally by the intracellular iron concentration. DMT1 was detected throughout the cell body and processes of OPCs where colocalizes partially with the Tfr. Interestingly, DMT1 was highly concentrated in the cell nucleus. 
A

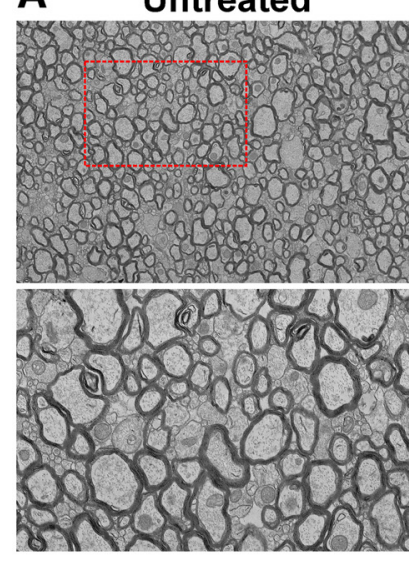

C

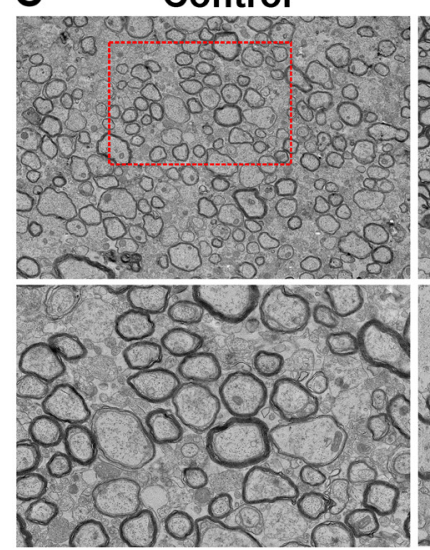

E

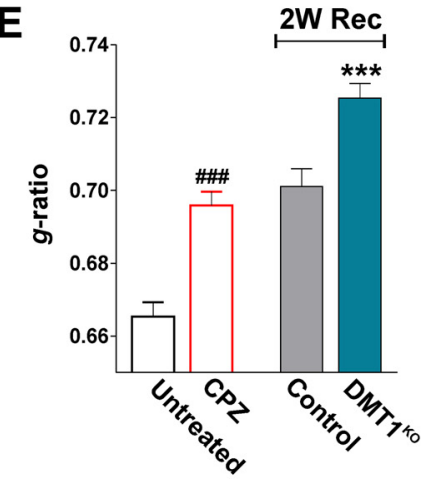

CPZ

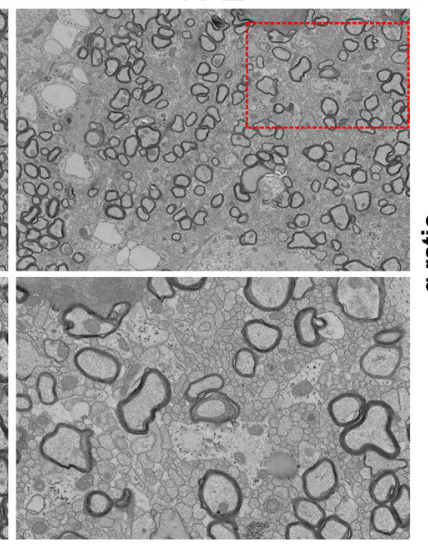

NG2-DMT1 ${ }^{\text {ko }}$

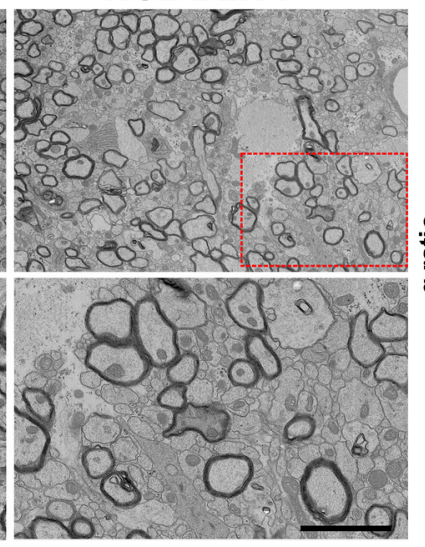

F

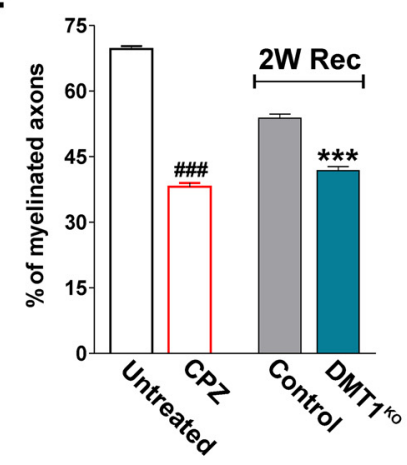

B

D
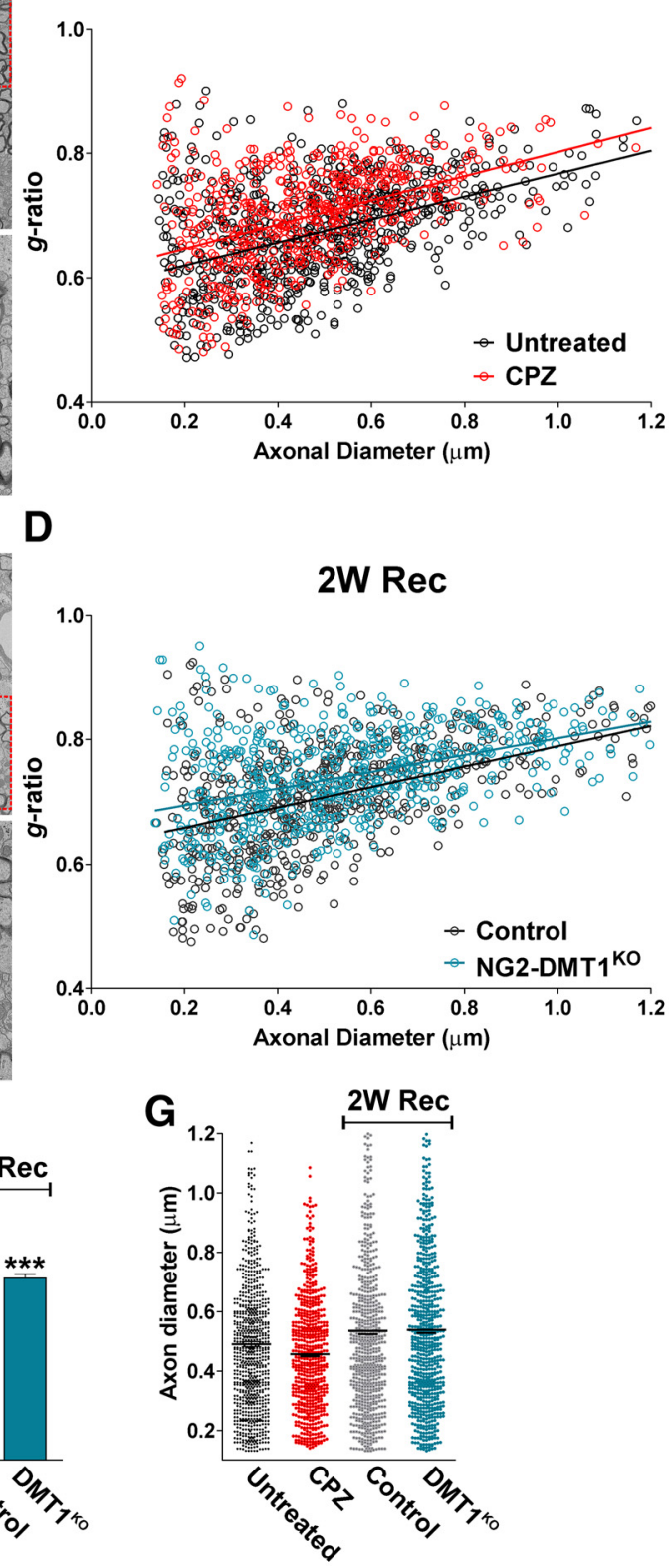

Figure 11. Electron microscopy of the NG2-DMT1 ${ }^{\mathrm{K} 0}$ corpus callosum during remyelination. $A, C$, Electron micrographs of axons in the corpus callosum of untreated animals (untreated), mice treated with cuprizone for 7 weeks (CPZ) and control and NG2-DMT1 ${ }^{\mathrm{KO}}$ mice at 2 weeks of recovery (2W Rec). Scale bar: (in C) top, $8 \mu \mathrm{m}$, bottom, $2 \mu \mathrm{m}$. B, D, Scatter plot of g-ratio values. The lines represent the regression equation with $95 \%$ confidence intervals. Untreated: $r^{2}, 0.2500$; slope, $0.1841 ; 1 /$ slope, 5.431; $F, 257.4 ;$; PZ: $r^{2}, 0.2024 ;$ slope, $0.1942 ; 1 /$ slope, 5.151; $F, 146.9 ;$ Control: $r^{2}$, 0.2971 ; slope, $0.1627 ; 1 /$ slope, $6.145 ; F, 274.7$; NG2-DMT1 ${ }^{\mathrm{KO}}: r^{2}, 0.1878$; slope, $0.1338 ; 1 /$ slope, $7.476 ; F, 142.5$. $E$, Mean g-ratio values. Exact $p$ values from left to right: $<0.0001 ; 0.0001$. $F$, Percentage of myelinated axons. Exact $p$ values from left to right: $<0.0001 ;<0.0001$. G, Mean axonal diameter of myelinated axons. Exact $p$ values from left to right: $0.0672 ; 0.8373$. Comparisons between experimental groups were made by one-way ANOVA followed by Bonferroni's multiple-comparison test. Values are expressed as the mean \pm SEM. Four animals per experimental group and 150 fibers per animal were analyzed. \#\# $p<0.001$ vs untreated; ${ }^{* *} p<0.001$ vs control.

DMT1 was also found in the nucleus of PC12 cells (Garrick et al., 2003), sympathetic neurons and human medulloblastoma cells in vitro as well as in situ (Roth et al., 2000). The function of DMT1 in the cell nucleus is currently unknown; perhaps DMT1 sequesters iron in the nucleus or carries iron there. In doing so, it may signal an aspect of iron status or it may serve as a signal of iron status itself in OPCs.

In contrast to the Belgrade rat (Burdo et al., 1999, 2001) or classical animal models of dietary iron restriction, which display the broad brain iron deficiency resulting from impaired uptake of iron from the gut or traversing the blood-brain barrier, the NG2-
DMT1 ${ }^{\text {KO }}$ and Sox10-DMT1 ${ }^{\text {KO }}$ mice exhibit iron deficiency only in OLs. Perl's histochemistry performed on NG2-DMT1 ${ }^{\mathrm{KO}}$ mice revealed a substantial reduction in the number of iron-positive OLs without changes in the average iron staining of cortical neurons or in the normal brain iron distribution. Therefore, these $\mathrm{DMT}{ }^{\mathrm{KO}}$ mice are the first models of OL iron deficiency. For the first time, we were able to study iron deficiency in OLs without the interference of systemic hypoferremia and the associated anemia. Thus, all changes in the development and myelination of OLs presented in this work can be entirely attributed to iron deficiency in the OL lineage. Nevertheless, we cannot exclude the 
possibility that DMT1 modulates OPC development and myelination by facilitating the incorporation of divalent metals other than iron. DMT1 can potentially transport other divalent cations, including magnesium, cadmium, zinc, cobalt, nickel, and copper (Gunshin et al., 1997). Brain myelin contains magnesium, zinc, and copper, and it is speculated that such metals play a role in membrane as cofactors of enzymes and possibly also in myelin structure. For instance, zinc appears to stabilize the myelin sheath by binding MBP in the presence of phosphate and this results in MBP aggregation (Riccio et al., 1995; Tsang et al., 1997). Baran et al. (2010) have recently shown that copper and zinc induce MBP compaction in vitro, suggestive of a tertiary conformation that may reflect its arrangement in mature myelin. Perhaps, DMT1 is required to uptake and concentrate divalent metals in young myelin sheaths to stimulate myelin compaction and stabilization.

\section{A role for DMT1 in the remyelination of the adult brain}

Remyelination requires the recruitment of OPCs to demyelinated lesions followed by their maturation into myelin-forming OLs. Iron is required in a variety of enzymes that influence myelin formation, including those that regulate metabolism, proliferation, and differentiation of OPCs, and the deposition of myelin membranes. Iron deficiency is associated with impairments in OL well being and remyelination (Stephenson et al., 2014). It has been shown that iron-deficient OLs and reduced iron availability lead to declines in OPC maturation and remyelination following injury (Schonberg and McTigue, 2009, Schulz et al., 2012). Additionally, several studies have shown global alterations in iron levels in the brains of patients with multiple sclerosis (MS). A significant decrease of iron in OLs and in the normal-appearing white matter was found in the brain of humans with chronic MS (Hametner et al., 2013). In active MS lesions, iron is released from dying OLs, resulting in extracellular accumulation of iron and uptake into microglia and macrophages (Williams et al., 2012). Furthermore, cellular degeneration in MS lesions leads to waves of iron liberation, which may propagate neurodegeneration together with inflammatory oxidative bursts.

We tested the role of DMT1 in demyelination and remyelination using the cuprizone model of myelin injury and repair (Armstrong et al., 2002, 2006; Paez et al., 2012). Our data suggest that after demyelination, DMT1 is critical for newly generated OPCs to incorporate iron and efficiently remyelinate demyelinated axons. We have found that DMT1-deficient OPCs mature slower than control cells and are less effective in remyelinating several structures of the adult brain including the corpus callosum and cortex. After 2 weeks of recovery, the control group showed a significant increase in the percentage of myelinated axons $(\sim 10 \%)$, without changes in the average g-ratio. These data reflect the normal remyelination process in which newly remyelinated axons are usually surrounded by thinner myelin. In contrast, DMT1 ${ }^{\mathrm{KO}}$ mice presented a marginal increase in the percentage of myelinated axons $(\sim 3 \%)$ with an important enlargement in the average g-ratio at 2 weeks of recovery. These findings reveal the inability of DMT $1{ }^{\mathrm{KO}} \mathrm{OPC}$ to efficiently remyelinate demyelinated axons and as a result more myelin is probably lost due to axonal damage.

The involvement of DMT1 in anemia, iron overload disorders, and neurodegenerative diseases makes their pharmacological modulation a promising therapeutic strategy. Pharmacological modulators for DMT1 are actively being developed (Buckett and Wessling-Resnick, 2009; Montalbetti et al., 2015; Seo et al., 2016). We believe that after demyelination, DMT1 is critical for newly generated OPCs to reuptake iron liberated from expiring OLs; thus, the activation of DMT1 in OPCs during the remyelination process may promote recovery. A small molecule capable of crossing the blood-brain barrier and specifically activating DMT1 in OPCs will be ideal. Further studies regarding cellular location, protein structure, and specific OL DMT1 isoforms will be necessary to achieve this objective. In summary, we have established that DMT1 is essential for normal OPC development and for iron uptake during the first steps of OPC maturation. Since iron accumulation by OLs is indispensable for myelination, understanding the iron incorporation mechanism as well as the molecules involved is critical to design new therapeutic approaches to intervene in diseases in which the myelin sheath is damaged or lost.

\section{References}

Algarín C, Peirano P, Garrido M, Pizarro F, Lozoff B (2003) Iron deficiency anemia in infancy: long-lasting effects on auditory and visual system functioning. Pediatr Res 53:217-223. CrossRef Medline

Amur-Umarjee S, Phan T, Campagnoni AT (1993) Myelin basic protein mRNA translocation in oligodendrocytes is inhibited by astrocytes in vitro. J Neurosci Res 36:99-110. CrossRef Medline

Armstrong RC, Le TQ, Frost EE, Borke RC, Vana AC (2002) Absence of fibroblast growth factor 2 promotes oligodendroglial repopulation of demyelinated white matter. J Neurosci 22:8574-8585. CrossRef Medline

Armstrong RC, Le TQ, Flint NC, Vana AC, Zhou YX (2006) Endogenous cell repair of chronic demyelination. J Neuropathol Exp Neurol 65:245256. CrossRef Medline

Badaracco ME, Ortiz EH, Soto EF, Connor J, Pasquini JM (2008) Effect of transferrin on hypomyelination induced by iron deficiency. J Neurosci Res 86:2663-2673. CrossRef Medline

Baran C, Smith GS, Bamm VV, Harauz G, Lee JS (2010) Divalent cations induce a compaction of intrinsically disordered myelin basic protein. Biochem Biophys Res Commun 391:224-229. CrossRef Medline

Beard J (2007) Recent evidence from human and animal studies regarding iron status and infant development. J Nutr 137:524S-530S. CrossRef Medline

Beard JL, Wiesinger JA, Connor JR (2003) Pre- and postweaning iron deficiency alters myelination in sprague-dawley rats. Dev Neurosci 25:308315. CrossRef Medline

Benkovic SA, Connor JR (1993) Ferritin, transferrin, and iron in selected regions of the adult and aged rat brain. J Comp Neurol 338:97-113. CrossRef Medline

Buckett PD, Wessling-Resnick M (2009) Small molecule inhibitors of divalent metal transporter 1. Am J Physiol Gastrointest Liver Physiol 296: G798-G804. CrossRef Medline

Burdo JR, Martin J, Menzies SL, Dolan KG, Romano MA, Fletcher RJ, Garrick MD, Garrick LM, Connor JR (1999) Cellular distribution of iron in the brain of the belgrade rat. Neuroscience 93:1189-1196. CrossRef Medline

Burdo JR, Menzies SL, Simpson IA, Garrick LM, Garrick MD, Dolan KG, Haile DJ, Beard JL, Connor JR (2001) Distribution of divalent metal transporter 1 and metal transport protein 1 in the normal and belgrade rat. J Neurosci Res 66:1198-1207. CrossRef Medline

Carlson ES, Tkac I, Magid R, O’Connor MB, Andrews NC, Schallert T, Gunshin H, Georgieff MK, Petryk A (2009) Iron is essential for neuron development and memory function in mouse hippocampus. J Nutr 139: 672-679. CrossRef Medline

Cheli VT, Santiago González DA, Namgyal Lama T, Spreuer V, Handley V, Murphy GG, Paez PM (2016) Conditional deletion of the L-type calcium channel $\mathrm{Ca}_{\mathrm{V}} 1.2$ in oligodendrocyte progenitor cells affects postnatal myelination in mice. J Neurosci 36:10853-10869. CrossRef Medline

Connor JR (1994) Iron acquisition and expression of iron regulatory proteins in the developing brain: manipulation by ethanol exposure, iron deprivation and cellular dysfunction. Dev Neurosci 16:233-247. CrossRef Medline

Connor JR, Menzies SL (1995) Cellular management of iron in the brain. J Neurol Sci 134 [Suppl]:33-44. CrossRef Medline

Connor JR, Snyder BS, Arosio P, Loeffler DA, LeWitt P (1995) A quantitative analysis of isoferritins in select regions of aged, parkinsonian, and Alzheimer's diseased brains. J Neurochem 65:717-724. CrossRef Medline Dwork AJ, Schon EA, Herbert J (1988) Nonidentical distribution of trans- 
ferrin and ferric iron in human brain. Neuroscience 27:333-345. CrossRef Medline

Erikson KM, Aschner M (2006) Increased manganese uptake by primary astrocyte cultures with altered iron status is mediated primarily by divalent metal transporter. Neurotoxicology 27:125-130. CrossRef Medline

Fleming MD, Romano MA, Su MA, Garrick LM, Garrick MD, Andrews NC (1998) Nramp2 is mutated in the anemic belgrade (b) rat: evidence of a role for Nramp2 in endosomal iron transport. Proc Natl Acad Sci U S A 95:1148-1153. CrossRef Medline

Franklin KBJ, Paxinos G (2008) The mouse brain in steriotaxic coordinates. 3. New York: Academic.

Garcia-Gonzalez D, Murcia-Belmonte V, Clemente D, De Castro F (2013) Olfactory system and demyelination. Anat Rec (Hoboken) 296:14241434. CrossRef Medline

Garrick MD, Dolan KG, Horbinski C, Ghio AJ, Higgins D, Porubcin M, Moore EG, Hainsworth LN, Umbreit JN, Conrad ME, Feng L, Lis A, Roth JA, Singleton S, Garrick LM (2003) DMT1: a mammalian transporter for multiple metals. Biometals 16:41-54. CrossRef Medline

Grantham-McGregor S, Ani C (2001) A review of studies on the effect of iron deficiency on cognitive development in children. J Nutr 31:649S666S. CrossRef Medline

Gruenheid S, Cellier M, Vidal S, Gros P (1995) Identification and characterization of a second mouse nramp gene. Genomics 25:514-525. CrossRef Medline

Gunshin H, Mackenzie B, Berger UV, Gunshin Y, Romero MF, Boron WF, Nussberger S, Gollan JL, Hediger MA (1997) Cloning and characterization of a mammalian proton-coupled metal-ion transporter. Nature 388: 482-488. CrossRef Medline

Gunshin H, Fujiwara Y, Custodio AO, Direnzo C, Robine S, Andrews NC (2005) Slc11a2 is required for intestinal iron absorption and erythropoiesis but dispensable in placenta and liver. J Clin Invest 115:1258-1266. CrossRef Medline

Hametner S, Wimmer I, Haider L, Pfeifenbring S, Brück W, Lassmann H (2013) Iron and neurodegeneration in the multiple sclerosis brain. Ann Neurol 74:848-861. CrossRef Medline

Hill JM, Switzer RC 3rd (1984) The regional distribution and cellular localization of iron in the rat brain. Neuroscience 11:595-603. CrossRef Medline

Hubert N, Hentze MW (2002) Previously uncharacterized isoforms of divalent metal transporter (DMT)-1: implications for regulation and cellular function. Proc Natl Acad Sci U S A 99:12345-12350. CrossRef Medline

Islam MS, Tatsumi K, Okuda H, Shiosaka S, Wanaka A (2009) Olig2expressing progenitor cells preferentially differentiate into oligodendrocytes in cuprizone-induced demyelinated lesions. Neurochem Int 54: 192-198. CrossRef Medline

Laranjeira C, Sandgren K, Kessaris N, Richardson W, Potocnik A, Vanden Berghe P, Pachnis V (2011) Glial cells in the mouse enteric nervous system can undergo neurogenesis in response to injury. J Clin Invest 121:3412-3424. CrossRef Medline

Larkin EC, Rao GA (1990) Importance of fetal and neonatal iron: adequacy for normal development of central nervous system. In: Brain, behavior and iron in the infant diet (Dobbing J, ed), pp 43-63. London: Springer.

Lee PL, Gelbart T, West C, Halloran C, Beutler E (1998) The human Nramp2 gene: characterization of the gene structure, alternative splicing, promoter region and polymorphisms. Blood Cells Mol Dis 24:199-215. CrossRef Medline

Ludwin SK (1978) Central nervous system demyelination and remyelination in the mouse: an ultrastructural study of cuprizone toxicity. Lab Invest 39:597-612. Medline

Matsushima GK, Morell P (2001) The neurotoxicant, cuprizone, as a model to study demyelination and remyelination in the central nervous system. Brain Pathol 11:107-116. Medline

Meguro R, Asano Y, Odagiri S, Li C, Iwatsuki H, Shoumura K (2007) Nonheme-iron histochemistry for light and electron microscopy: a historical, theoretical and technical review. Arch Histol Cytol 70:1-19. CrossRef Medline

Montalbetti N, Simonin A, Simonin C, Awale M, Reymond JL, Hediger MA (2015) Discovery and characterization of a novel non-competitive inhibitor of the divalent metal transporter DMT1/SLC11A2. Biochem Pharmacol 96:216-224. CrossRef Medline
Moos T, Rosengren Nielsen T, Skjørringe T, Morgan EH (2007) Iron trafficking inside the brain. J Neurochem 103:1730-1740. CrossRef Medline

Morath DJ, Mayer-Pröschel M (2001) Iron modulates the differentiation of a distinct population of glial precursor cells into oligodendrocytes. Dev Biol 237:232-243. CrossRef Medline

Mosmann T (1983) Rapid colorimetric assay for cellular growth and survival: application to proliferation and cytotoxicity assays. J Immunol Methods 65:55-63. CrossRef Medline

Ortiz E, Pasquini JM, Thompson K, Felt B, Butkus G, Beard J, Connor JR (2004) Effect of manipulation of iron storage, transport, or availability on myelin composition and brain iron content in three different animal models. J Neurosci Res 77:681-689. CrossRef Medline

Oski FA, Honig AS, Helu B, Howanitz P (1983) Effect of iron therapy on behavior performance in nonanemic, iron-deficient infants. Pediatrics 71:877-880. Medline

Paez PM, Cheli VT, Ghiani CA, Spreuer V, Handley VW, Campagnoni AT (2012) Golli myelin basic proteins stimulate oligodendrocyte progenitor cell proliferation and differentiation in remyelinating adult mouse brain. Glia 60:1078-1093. CrossRef Medline

Ponka P (1997) Tissue-specific regulation of iron metabolism and heme synthesis: distinct control mechanisms in erythroid cells. Blood 89:1-25. Medline

Riccio P, Giovannelli S, Bobba A, Romito E, Fasano A, Bleve-Zacheo T, Favilla R, Quagliariello E, Cavatorta P (1995) Specificity of zinc binding to myelin basic protein. Neurochem Res 20:1107-1113. CrossRef Medline

Roncagliolo M, Garrido M, Walter T, Peirano P, Lozoff B (1998) Evidence of altered central nervous system development in infants with iron deficiency anemia at 6 mo: delayed maturation of auditory brainstem responses. Am J Clin Nutr 68:683-690. CrossRef Medline

Rosato-Siri MV, Badaracco ME, Ortiz EH, Belforte N, Clausi MG, Soto EF, Bernabeu R, Pasquini JM (2010) Oligodendrogenesis in iron-deficient rats: effect of apotransferrin. J Neurosci Res 88:1695-1707. CrossRef Medline

Roth JA, Horbinski C, Feng L, Dolan KG, Higgins D, Garrick MD (2000) Differential localization of divalent metal transporter 1 with and without iron response element in rat PC12 and sympathetic neuronal cells. J Neurosci 20:7595-7601. CrossRef Medline

Rouault TA (2013) Iron metabolism in the CNS: implications for neurodegenerative diseases. Nat Rev Neurosci 14:551-564. CrossRef Medline

Santiago González DA, Cheli VT, Zamora NN, Namgyal Lama TN, Spreuer V, Murphy GG, Paez PM (2017) Conditional deletion of the L-type calcium channel $\mathrm{Ca}_{\mathrm{V}} 1.2$ in NG2 positive cells delay remyelination in mice. J Neurosci 37:10038-10051. CrossRef Medline

Schonberg DL, McTigue DM (2009) Iron is essential for oligodendrocyte genesis following intraspinal macrophage activation. Exp Neurol 218:6474. CrossRef Medline

Schulz K, Kroner A, David S (2012) Iron efflux from astrocytes plays a role in remyelination. J Neurosci 32:4841-4847. CrossRef Medline

Seo YA, Kumara R, Wetli H, Wessling-Resnick M (2016) Regulation of divalent metal transporter-1 by serine phosphorylation. Biochem J 473: 4243-4254. CrossRef Medline

Skjørringe T, Burkhart A, Johnsen KB, Moos T (2015) Divalent metal transporter 1 (DMT1) in the brain: implications for a role in iron transport at the blood-brain barrier, and neuronal and glial pathology. Front Mol Neurosci 8:19. CrossRef Medline

Song N, Jiang H, Wang J, Xie JX (2007) Divalent metal transporter 1 upregulation is involved in the 6-hydroxydopamine-induced ferrous iron influx. J Neurosci Res 85:3118-3126. CrossRef Medline

Sperber BR, McMorris FA (2001) Fyn tyrosine kinase regulates oligodendroglial cell development but is not required for morphological differentiation of oligodendrocytes. J Neurosci Res 63:303-312. CrossRef Medline

Stephenson E, Nathoo N, Mahjoub Y, Dunn JF, Yong VW (2014) Iron in multiple sclerosis: roles in neurodegeneration and repair. Nat Rev Neurol 10:459-468. CrossRef Medline

Suzumura A, Bhat S, Eccleston PA, Lisak RP, Silberberg DH (1984) The isolation and long-term culture of oligodendrocytes from newborn mouse brain. Brain Res 324:379-383. CrossRef Medline

Todorich B, Pasquini JM, Garcia CI, Paez PM, Connor JR (2009) Oligodendrocytes and myelination: the role of iron. Glia 57:467-478. CrossRef Medline 
Tripathi RB, Clarke LE, Burzomato V, Kessaris N, Anderson PN, Attwell D, Richardson WD (2011) Dorsally and ventrally derived oligodendrocytes have similar electrical properties but myelinate preferred tracts. J Neurosci 31:6809-6819. CrossRef Medline

Tsang D, Tsang YS, Ho WK, Wong RN (1997) Myelin basic protein is a zinc-binding protein in brain: possible role in myelin compaction. Neurochem Res 22:811-819. CrossRef Medline

Veuthey T, Wessling-Resnick M (2014) Pathophysiology of the belgrade rat. Front Pharmacol 5:82. CrossRef Medline

Vivot RM, Goitia B, Usach V, Setton-Avruj PC (2013) DMT1 as a candidate for non-transferrin-bound iron uptake in the peripheral nervous system. Biofactors 39:476-484. CrossRef Medline
Williams R, Buchheit CL, Berman NE, LeVine SM (2012) Pathogenic implications of iron accumulation in multiple sclerosis. J Neurochem 120:725. CrossRef Medline

Zhang Y, Chen K, Sloan SA, Bennett ML, Scholze AR, O'Keeffe S, Phatnani HP, Guarnieri P, Caneda C, Ruderisch N, Deng S, Liddelow SA, Zhang C, Daneman R, Maniatis T, Barres BA, Wu JQ (2014) An RNAsequencing transcriptome and splicing database of glia, neurons, and vascular cells of the cerebral cortex. J Neurosci 34:11929-11947. CrossRef Medline

Zhu X, Hill RA, Dietrich D, Komitova M, Suzuki R, Nishiyama A (2011) Age-dependent fate and lineage restriction of single NG2 cells. Development 138:745-753. CrossRef Medline 